This Draft: March 22, 2005.

\title{
Reputation Effects in Trading on the New York Stock Exchange
}

\author{
by
}

\author{
Robert Battalio \\ Mendoza College of Business \\ University of Notre Dame
}

\author{
Andrew Ellul \\ Kelley School of Business \\ Indiana University
}

\author{
Robert Jennings ${ }^{\dagger}$ \\ Kelley School of Business \\ Indiana University
}

Abstract: Theory suggests that reputations, developed in repeated face-to-face interactions, allow nonanonymous, floor-based trading venues to attenuate adverse selection in the trading process. We identify instances when stocks listed on the New York Stock Exchange (NYSE) experience a non-trivial relocation on the trading floor for reasons unrelated to execution quality. Although the specialist follows the stock to its new location, most floor brokers do not. We use this natural experiment to determine whether reputation appears to affect trading costs. We find a discernable increase in the cost of liquidity in the days surrounding a stock's relocation. The increase is more pronounced for stocks with higher adverse selection and greater broker turnover. Using NYSE audit-trail data, we find that the floor brokers relocating with the stock obtain lower trading costs than those brokers who do not move and those that begin trading post-move in the days surrounding the move. Together, these results suggest that reputation plays an important role in the liquidity provision process on the floor of the NYSE.

Notes: We thank the New York Stock Exchange for providing data. We thank Markus Brunnermeier, Shane Corwin, Thierry Foucault, Frank Hatheway, Christian Lundblad, Thomas McInish, Marco Pagano, Tavy Ronen, Katherine Ross, Duane Seppi, Ingrid Werner and participants in seminars at Indiana University, London School of Economics, University of Kansas, University of Memphis, University of Notre Dame, Rutgers University, University of Utah and participants at the Financial Economics and Accounting Conference at the University of Southern California. The opinions expressed in the paper do not necessarily reflect those of the employees, members, or officers of the New York Stock Exchange.

${ }^{\dagger}$ Corresponding author: Robert Jennings, 1309 E. $10^{\text {th }}$ Street, Bloomington, IN 47405; (812) 855-2696. 


\section{Reputation Effects in Trading on the New York Stock Exchange}

Abstract: Theory suggests that reputations, developed in repeated face-to-face interactions, allow nonanonymous, floor-based trading venues to attenuate adverse selection in the trading process. We identify instances when stocks listed on the New York Stock Exchange (NYSE) experience a non-trivial relocation on the trading floor for reasons unrelated to execution quality. Although the specialist follows the stock to its new location, most floor brokers do not. We use this natural experiment to determine whether reputation appears to affect trading costs. We find a discernable increase in the cost of liquidity in the days surrounding a stock's relocation. The increase is more pronounced for stocks with higher adverse selection and greater broker turnover. Using NYSE audit-trail data, we find that the floor brokers relocating with the stock obtain lower trading costs than those brokers who do not move and those that begin trading post-move in the days surrounding the move. Together, these results suggest that reputation plays an important role in the liquidity provision process on the floor of the NYSE.

Klein (1997) documents that reputations have played a role in facilitating trade since at least the Middle Ages by reducing the informational asymmetry between buyers and sellers described in Akerloff (1970). Diamond (1991), Boot, Greenbaum, and Thakor (1993), and Wilner (2000) each model the role of reputation in different financial-market settings. Despite their perceived importance, however, there is little direct empirical evidence as to the economic value of relationships in financial markets. De Jong, et al. (1985) and others demonstrate the importance of reputations in experimental financial markets, but it is difficult to generalize their results to real world settings. Carter and Manaster (1990) find that an underwriter's reputation is associated with the returns initial public equity offerings provide investors, but there appears to be no empirical evidence of a reputation-effect in secondary equity markets. ${ }^{1}$ More recently, researchers have documented the economic importance of electronic reputation systems in Internet auctions. ${ }^{2}$ Although these studies find customer and seller feedback ratings are economically important, they likely

\footnotetext{
${ }^{1}$ Cohen (2003) notes that Dimensional Fund Advisors (DFA) "reduced adverse selection problems both by dealing with parties that had shown themselves to be trustworthy and by taking steps to encourage greater trustworthiness in trading partners. DFA had a vast roster of regular sellers - brokerage firms that had a consistent need to trade large blocks of stock for their clients. Preferred sellers were firms (and individuals within those firms) that consistently made full disclosure to DFA of everything they knew about the stock. Such brokers would be more likely to get a deal done and to negotiate a less steep discount. DFA would be more cautious with brokers with whom it was less familiar. Such sellers might find DFA wanted to do smaller deals until a trusting relationship had been established, or that DFA might negotiate a particularly steep discount because of the greater risk associated with the possibility of being 'picked off'."
}

${ }^{2}$ See Dellarocas (2004). 
understate the value of repeated, face-to-face interactions. ${ }^{3}$ In this paper, we use a natural experiment to evaluate the economic importance of relationships on the floor of the New York Stock Exchange (NYSE).

NYSE trading is organized so that all orders in a security go to one physical location on the floor where exchange members wishing to trade that security gather. One individual, the specialist, trades only the securities assigned to that location. Other individuals, floor brokers, might trade securities at several locations but usually handle all of their brokerage firm's orders in a particular security. The regular face-toface interactions between specialists and floor brokers and between different floor brokers allow reputations to form - reputations that Benveniste, et. al. (1992), Pagano and Roell (1992), Chan and Weinstein (1993), and Desgranges and Foucault (2005) argue play a role in a security's trading process. If relationships are important in attenuating adverse selection problems, then exogenous disruptions to these relationships provide opportunities to examine their economic importance. We investigate the joint hypothesis that trading relationships are important and that these relationships affect the trading process by examining the liquidity costs for a sample of securities changing the location at which they trade on the floor of the NYSE.

Benveniste, Marcus, and Wilhelm (1992) develop a model of the specialist trading system in which specialists improve the welfare of both exchange members and the investing public by reducing incentives to exploit information advantages. Because of repeated dealings with floor brokers, specialists can impose the cost of informed trading onto traders using private information to disadvantage other traders by assessing sanctions (e.g., by providing less favorable future prices, by being less willing to improve quoted prices, or by being less willing to fill large orders at quoted prices). If a trader bears the full cost of informed trading instead of only the pro rata cost of such behavior, then that trader is less likely to impose adverse selection costs on others. This ability to sanction allows specialists to narrow bid-ask spreads without reducing market-making profitability. In a multi-period setting, Chan and Weinstein (1993) also conclude that

\footnotetext{
${ }^{3}$ Granovetter (1985) notes that, although such generalized information is better than nothing, the best information arises from an individual's own dealings with others.
} 
specialists can quote tighter bid-ask spreads because of repeated dealings with floor brokers. In their model, specialists reward brokers revealing private information by providing them with information about standing orders. This is in stark contrast to the single-period models of Kyle (1985) and others which, by design, do not consider the benefits of cooperative behavior.

We identify reallocations of trading locations by specialist firms, reorganizations of the NYSE floor due to specialist-firm mergers, and the opening of a new trading floor. None of these events are the result of endogenous changes in trading costs or are associated with NYSE disciplinary actions. If the imminent departure of a specialist from the current trading location suggests to floor brokers that the specialist cannot sanction undesirable and/or reward desirable behavior in the future, then we might observe changes in trading behavior in the days leading up to a stock's relocation on the NYSE floor. Specifically, if the floor broker will not be subject to a particular specialist's power to sanction or reward (because the specialist moves and the floor broker does not), then trading costs could increase prior to the move to compensate for the possibility of additional adverse selection risk. In theory, the old equilibrium unravels when the change in location is anticipated. If trading relationships matter and these relationships are not established instantaneously at the new location, then the disruption in relationships caused by the relocation also might manifest itself in a security's trading for some time after the change in location. In summary, if relationships are important, then we expect to find an increase in trading costs prior to and a disruption in the trading process after the date that securities change location on the NYSE floor.

Alternatively, it is possible that the floor broker community is relatively unimportant to the specialist. For example, relationships with individual floor brokers might be irrelevant because much of the trading strategy is determined by traders at the brokerage firm's trading desk and not by the broker on the NYSE floor. That is, knowing that investors and the broker's traders are unaffected by NYSE space reallocation decisions, the specialist behaves no differently immediately before and after the change in location. In addition, because floor brokers at the new location work for the same brokerage firms as those at the former 
location, the specialist can punish/reward the new brokers for the behavior of their fellow employees at the prior trading location. These arguments suggest there might be no change in trading behavior when a security's trading location on the floor of the NYSE changes.

We begin our analysis by using proprietary NYSE data to demonstrate that individual floor brokers typically do not follow a stock to its new trading location. We find that fewer than five percent of brokers executing trades in a particular stock prior to its relocation also trade in the post-move sample period. This verifies our claim that the move disrupts relationships. Next, using the NYSE Trade and Quote (TAQ) database, we examine spreads around the time securities change their trading location on the floor of the NYSE. We find a discernible increase in liquidity costs when a stock moves. Consistently with theory, the increase in trading costs is positively related to the measured adverse selection and the broker turnover associated with the moving security.

Using proprietary NYSE data, we examine the execution costs of individual floor brokers who do and do not trade the stock at both locations. In the days just prior to the move, we find that pre-move trading costs for brokers moving with the specialist to the stock's new trading location are somewhat less than the trading costs faced by non-moving brokers. These two groups of brokers face similar trading costs in times further from the relocation day. We also find that post-move trading costs paid by moving brokers are lower than those paid by the brokers who are new to the trading crowd. This result is especially strong in the first few days after the move when the specialist is trading with a new crowd and is true regardless of whether the trade is between two moving brokers (who have dealt with each other previously) or between the specialist and a moving broker (who also have traded with each other previously). Non-moving (new) brokers are at a trading-cost disadvantage when trading with the specialist or with a non-moving broker. This result is particularly strong in a multivariate setting for stocks with high levels of adverse selection. Together, these results provide the first direct evidence that face-to-face relationships might give floor-based exchanges an advantage over anonymous electronic trading systems in executing certain orders. 
Our results suggest that electronic venues may not render the floor-based NYSE obsolete. Although electronic markets are faster and cheaper to operate and monitor than floor-based markets, a large empirical literature suggests floor-based exchanges excel at handling orders that are potentially motivated by private information. ${ }^{4}$ Our work is the first to empirically support theoretical arguments that individual relationships are a source of this comparative advantage. Although face-to-face interactions appear to be a comparative advantage of floor-based trading, it is not clear that this advantage alone outweighs the cost advantages and potential anonymity available on electronic trading venues.

The rest of the paper is organized as follows. Section I develops the hypotheses to be tested and introduces the data. Section II examines changes in trading costs around the specialist's location change using publicly available trade and quote data. Section III reviews in detail the trades of the moving and non-moving brokers using NYSE proprietary data. Section IV concludes.

\section{Hypothesis Development, Data, and Microstructure Variables}

\section{A. Hypotheses Development.}

The NYSE floor is organized to focus a security's trading at one physical location. Each location typically trades multiple securities; the exact number being determined by security characteristics such as trading volume. One individual, the specialist, trades only at that location and is responsible for maintaining a 'fair and orderly' market in the securities trading there. Other individuals, floor brokers, represent customer trading interests. Sofianos and Werner (2000) find that NYSE floor brokers executed trades corresponding to $44 \%$ of the value of all buys and sells in January and February of 1997. Because orders are time sensitive,

${ }^{4}$ See, e.g., Chakravarty (2002), Venkataraman (2001), Garfinkel and Nimalendran (2003), Barclay, Hendershott and McCormick (2003), Waisburd (2003), Bessembinder and Venkataraman (2004), Theissen (2000), and Handa, Schwartz and Tiwari (2004). Boehmer, Saar and Yu (2004), Madhavan and Panchapagesan (2000), Corwin and Lipson (2000), Coval and Shumway(2001) each present evidence that suggests the floor is informationally rich. Baker and Iyer (1992) examine trading crowds in a national option exchange and find that network structure influences price volatility and expected trading volume. They interpret their results as suggesting that the structure of the real communication network among investors may influence market behavior. 
the physical area a floor broker covers typically is limited to something less than the entire exchange floor. In most cases, a floor broker executes all of their firm's orders in a given stock. The organization of trading on the NYSE suggests that specialists and floor brokers trade with each other repeatedly. Furthermore, because trading on an exchange floor is face-to-face, the trading relationships among the floor community are more likely to play a role in the trading process than in an anonymous electronic setting. ${ }^{5}$

Theory suggests that relationships between floor brokers and specialists have important implications for the trading process observed on an exchange. Benveniste, Marcus and Wilhelm(1992) argue that repeated face-to-face interactions on the floor of the NYSE allow specialists (and other floor brokers) to sanction floor brokers who exploit private information. ${ }^{6}$ For example, floor brokers obtaining favorable transaction prices by misrepresenting time-sensitive orders as liquidity trades to specialists or fellow floor brokers might find those parties less willing to trade with them in the future. Benveniste et. al. (1992) argue that the ability to sanction is important in constraining individual floor brokers from imposing adverse selection costs on the specialist and/or other brokers in the crowd. In the days leading up to a specialist's move, this constraint becomes relaxed for floor brokers who do not plan to follow the specialist to the new location. Specifically, floor brokers who do not expect to follow the specialist might become increasingly willing to trade on private information. Anticipating this possibility, specialists and other floor brokers might become more cautious when interacting with the floor brokers they expect to remain behind.

After the move is complete, the specialists and floor brokers regain their ability to sanction crowd members trading on private information. That is, the new floor community will, for the foreseeable future, be involved in repeated face-to-face trades. If the discipline argument is the sole driver of floor relationships, then we would expect trading to return to normal immediately after stocks relocate. However, in addition to

\footnotetext{
${ }^{5}$ Cao, Choe and Hatheway (1997), Corwin (1999), and Coughenour and Saad (2004) present evidence suggesting that a stock's trading characteristics are related to the specialist firm trading the stock.

${ }^{6}$ Chan and Weinstein (1993) reach similar conclusions, arguing specialists reward floor brokers that reveal private information regarding their orders by offering them tighter bid-ask spreads on future trades. Carlin, Lobo, and Viswanathan (2004) theoretically conclude that "traders cooperate through repeated interactions providing liquidity to each other."
} 
the discipline hypothesis, we posit that traders have trading reputations that take time to build. Although he focuses on borrower-lender relationships, Diamond (1989) presents a model in which reputation building affects how agents behave, and as a result, equilibrium prices. Diamond shows that borrowers alter their behavior to influence what lenders learn about them. Specifically, borrowers change their behavior to protect good reputations. If there is sufficient adverse selection, Diamond demonstrates that it takes time for market participants to build their reputations. In our setting, there typically are many new floor brokers in the crowd following the relocation of a specialist. Untilnew relationships are formed between the old and new members of the crowd, providing liquidity to new floor brokers is more risky than providing liquidity to those with established reputations. This suggests that liquidity providers will offer less favorable prices for orders handled by new floor brokers to compensate them for bearing the increased adverse selection risk.

Together, Benveniste et. al. (1992), Chan and Weinstein (1993) and Diamond (1989) suggest that we should see changes in the trading process in the days leading up to and immediately following the relocation of a specialist if crowd relationships are important in attenuating adverse selection. These theories suggest that the effective spreads paid by orders handled by floor brokers that leave (join) the crowd following a specialist's relocation will rise (fall) in the days leading up to (following) the move. Although these changes should occur in all relocated stocks, they should be most drastic in stocks with the highest levels of asymmetric information and stocks with the greatest turnover in floor brokers. As in Huang and Stoll (1997), we use the difference between the effective and realized spread as a proxy for the level of asymmetric information in a stock to investigate this conjecture. ${ }^{7}$ Following Bacidore and Sofianos (2002) and Huang and Stoll (1996), we construct a matched sample of stocks that do not move to control for changes in effective and realized spreads that are unrelated to the specialist's relocation.

\footnotetext{
${ }^{7}$ Our conclusions do not change when we use the proxies for adverse selection used by Bessembinder and Kaufman (1997), Stoll (2000), and Brennan and Subrahmanyam (1996).
} 


\section{B. Data.}

Our analysis uses three primary databases. We begin by identifying changes in location on the NYSE floor using 'post and panel' data obtained from the Exchange. We next use the NYSE's Trade and Quote (TAQ) database to analyze NYSE trading costs around the specialist relocations. Although these trading cost tests do not provide the sharpest tests of our hypotheses, they provide insight into the overall economic importance of stock relocations. Finally, we use proprietary consolidated equity audit-trail data (CAUD) obtained from the NYSE to examine whether effective spreads for orders handled by floor brokers that leave (join) the crowd following a specialist's relocation rise (remain the same) in the days leading up to (following) the move. The 'post and panel' data, the CAUD, and the TAQ data are described more fully below.

The NYSE's floor is divided into 20 (17 active) trading posts. Posts are subdivided into as many as 30 'panels,' each with a specialist. Panels are so-named due to the flat-screen panel above the specialist that lists the stocks trading at that location and other pertinent data. Thus, the combination of post (numbered one through twenty) and panel (lettered beginning at $\mathrm{A}$ in each post) provides a unique location on the floor. ${ }^{8}$ For example, as of January 2004 General Electric stock trades at Post 13 Panel M. It is the only stock trading there. AOL and five other stocks are traded by a specialist at Post 3 Panel O. The NYSE's post and panel data provide daily information about where stocks trade beginning in June 1999. We obtain these data from June 1999 through April 2003. To determine changes in location, we take the first difference of these data.

We are not interested in all changes in post and panel. We need the distance a stock moves to be large enough to suggest a clear turnover in the crowd trading the stock. The floor of the Exchange is divided into five 'rooms.' The 'Garage' contains posts one through four. The 'Main Room' consists of posts five through eleven. Posts 12 through 14 are in the 'Blue Room' and posts 15 through 17 (currently inactive) are in the 'Extended Blue Room.' Finally, 'Thirty Broad' contains posts 18 through 20. To be included in our

\footnotetext{
${ }^{8}$ A schematic of the floor can be seen at http://marketrac.nyse.com $/ \mathrm{mt} / \mathrm{index} . \mathrm{html}$.
} 
sample, a stock must move from one room to another. It is common for floor brokers to be assigned to a specific 'room' if the brokerage firm is large enough to have multiple brokers. This prevents a broker from having to cover too much territory, which slows order placement. The broker typically works from a single booth (e.g., the firm's booth in the Main Room) regardless of the mix of stocks trading in that room. Thus, if a stock changes rooms, it is likely to be traded in a different floor broker crowd than it was previously as the brokers in the new room begin coverage. Our sample consists of all location changes from June, 1999 through April, 2003 involving an entire panel of stocks switching rooms. We require that the panel of stocks remain constant (i.e., the specialist trades the same stocks before and after the switch in location). The fact that the entire panel of stocks changes location suggests that the specialist and stocks did not change, but that there is a potential change in the floor broker community.

We find six occasions during our sample period in which one or more panels of stocks remains together after a room change. Table I summarizes our sample.

\section{[Insert Table I.]}

The July 1999, the June 2000, and the March 2002 events appear to be internal reorganizations by one or more specialist firms. ${ }^{9}$ Although there are many of these reorganizations, these appear to be the only ones resulting in a panel of stocks changing rooms. The majority of our sample of location changes occur on three dates in 2000: November 20, December 11, and December 20. The November date is the opening of the 30 Broad trading floor, and the later two dates are apparently the result of specialist mergers. Specialist firms prefer to trade stocks at contiguous posts/panels due to efficiencies that can be gained in support staff. Thus, following specialist mergers, the Exchange typically reallocates space to accommodate the acquiring firm.

It is important to note that, to the best of our knowledge, these relocations are not due to the specialist providing poor-quality executions. Specialists are monitored by the Exchange and evaluated by floor brokers. Should the specialist provide unacceptable execution quality, the stock can be reallocated to

\footnotetext{
${ }^{9}$ There appears to be no publicly available official NYSE announcement stating that stocks will be changing locations.
} 
another specialist. This is not the case for our sample of relocations, which occur for reasons exogenous to trading costs. As a result, this setting should provide a relatively clean test for economically meaningful reputation effects.

To measure the broker turnover associated with these location changes, we acquire NYSE consolidated equity audit-trail data. CAUD provides, among other information, the counter-parties to each trade. For electronically submitted orders (SuperDOT), only the member firm's name is provided. For trades involving a floor broker, however, the broker's badge number (both buyer and seller badge numbers if both are floor brokers) is part of the record. The badge number uniquely identifies an individual member.

By examining CAUD for a period of time before and after the switch in location, we can estimate how many floor brokers follow the specialist to the new location on the floor. We obtain audit-trail data for two weeks before and after the switch. We assume that a broker trades at least once in each of those periods. If that is not true, then we mis-classify that broker as one that did not move to the new location (trades before, but not after) or one that began trading after the switch (trades after, but not before). Of the 915 broker badges trading the sample stocks prior to their relocation, only 34 (3.7\%) make trades in multiple rooms. Thus, very few floor brokers normally trade in multiple rooms. Table II provides some descriptive statistics regarding floor broker turnover around our sample relocations.

[Insert Table II.]

Prior to the switch date, the average sample stock has about 35 different floor brokers executing at least one trade (40 conditional on a stock having at least one pre-move trade). On average, fewer than two brokers (4.7\% of the 35.66) appear in both the pre- and the post-switch trade data. These brokers participate in about $2.7 \%$ of the trades, but trade $6.3 \%$ of the shares prior to the specialist's move. Thus, floor brokers following the specialist to the new location make fewer, but larger trades than the average floor broker.

In Panel B of Table II, we provide descriptive statistics regarding the pre-switch distribution of trading by brokers that do and do not have trades in both the pre- and post- move sample periods. Note that 
moving brokers, on average, have their trading activity concentrated in fewer locations than non-moving brokers (1.68 panels versus 3.08 panels). Fully one-half of the moving brokers trade at a single panel. For these brokers, it is no surprise that they move to the new location.

We compute effective spreads, realized spreads, and the corresponding adverse selection measure as in Huang and Stoll (1996) around specialist relocations using the NYSE's TAQ database, which contains intraday trades and quotes for all securities listed on the NYSE, the American Stock Exchange, and the Nasdaq Stock Market. Each quote record indicates the underlying stock, the trading venue posting the quote, the date and time of the quote, the bid and ask prices and quantities, and a condition code indicating whether the quote is an opening or closing quote. Each trade record indicates the underlying stock, the date and time the trade was reported, the venue reporting the trade, the transaction size and price, and codes indicating whether the trade is subsequently cancelled or is made with 'special' conditions. ${ }^{10}$ Following Bessembinder and Kaufman (1997) and others we eliminate trades with a Condition Code of ' $Z$ ' or ' $G$ ' and trades that have a Correction Code that is not equal to zero or one. At each moment in the trading day, a stock's National Best Bid and Offer (NBBO) is computed by taking the highest bid and the lowest offer (i.e., the best prices) quoted by venues on which the stock is traded. The computation of effective (realized) spreads requires trades matched with the National Best Bid and Offer at (five minutes after) trades are reported.

\section{Microstructure Variables.}

Effective spreads are used to examine the impact of specialist relocations on trading costs. The effective spread, which is the product of an indicator variable that equals 1 for buy orders and -1 for sell orders and twice the difference between the trade price and the midpoint of the execution-time NBBO, provides an estimate of the round trip cost of immediacy paid by liquidity demanders. Because the trade data provided by TAQ do not identify transactions as buys or sells, we use the Lee and Ready (1991) algorithm

\footnotetext{
${ }^{10}$ See the NYSE's TAQ2 User's Guide for an in-depth description of the TAQ database.
} 
to infer whether a trade is initiated by a buyer or seller. ${ }^{11}$ The Lee and Ready (LR) algorithm first attempts to classify a trade as a buy or a sell by comparing the trade's execution price to the prevailing quotes. Trades with execution prices above (below) the midpoint of the execution-time bid and offer prices are classified as buys (sells). To classify trades executed at the midpoint of the execution-time quotes, the LR algorithm looks to prior trades. If the execution price of the prior trade is lower (higher) than the current trade's execution price, the current trade is classified as a buy (sell). If the prior trade has the same execution price as the current trade, the LR algorithm moves backwards in time until it finds a prior trade with a different price and follows similar logic. The realized spread, computed as the product of an indicator variable that equals 1 for buy orders and -1 for sell orders and twice the absolute difference between the trade price and the midpoint of the NBBO prevailing five minutes after a trade is executed, provides an estimate of the gross trading revenue earned by liquidity providers. Finally, the adverse selection component of the spread as defined by Huang and Stoll (1996) is the difference between the effective spread (i.e., what investors pay) and the realized spread (i.e., what liquidity providers earn). Following Bacidore and Sofianos (2002) and others, we standardize each of our microstructure variables by the execution-time NBBO midpoint to control for variation in spreads due to residual differences in price levels.

To ensure that documented changes in trading costs are due to changes in the crowd (and not market events), we compare spreads for stocks that change locations with spreads for a matched sample of stocks that do not relocate. For each stock changing location, we find a similar, non-moving NYSE-listed security. We match on the basis of market capitalization, share price, trade volume, and share price volatility. For market capitalization, we use the year-end market capitalization from CRSP that immediately precedes a stock's relocation date. The remaining three matching variables are averages of daily values measured from event-day minus 100 through event-day minus 50. Share price is the average closing price, trade volume is

\footnotetext{
${ }^{11}$ Lee and Radhakrishna (2000), Odders-White (2000), and Finucane (2000) use the NYSE's TORQ database to test the Lee and Ready algorithm and document a success rate in excess of $85 \%$.
} 
the average number of trades in a day, and share price volatility is the natural log of the ratio of the high and the low trade prices in a day. Following Bacidore and Sofianos (2002) and Huang and Stoll (1996), we find the matching, non-moving stock that minimizes the following:

$$
\sum_{i=1}^{4}\left(\frac{c_{i}^{\text {Moving }}-c_{i}^{\text {Non-Moving }}}{\left(c_{i}^{\text {Moving }}+c_{i}^{\text {Non-Moving }}\right) / 2}\right)^{2}
$$

where $c_{i}^{\text {Moving }}$ denotes the value of the ith matching variable for the relocating stock, and where $\mathrm{c}_{\mathrm{i}}{ }^{\text {Non-Moving }}$ denotes the value of the ith matching variable for the stock that does not change locations. This minimization is done subject to the constraint that:

$$
\left|\frac{c_{i}^{\text {Moving }}-c_{i}^{\text {Mon-Moving }}}{\left(c_{i}^{\text {Moving }}+c_{i}^{\text {Mon-Moving }}\right) / 2}\right|<1
$$

for all i (i.e., for each of our four matching characteristics).

Some of our tests compare effective and realized spreads across stocks. Because low-priced stocks can have abnormally large relative spreads we eliminate relocating stocks and their controls on any day that either stock's average trade price is less than $\$ 5.00$ per share. We also eliminate stock days on which the relocating stock or its control have fewer than two trades. Table III provides descriptive statistics for our sample and control stocks with these screens in place.

\section{[Insert Table III.]}

Both sets of stocks have an average share price of about $\$ 26$ and have about 150 trades and 340,000 shares traded daily during the sample period. The mean effective spread is six or seven cents and the mean realized spread is about two cents. 


\section{NYSE Trading Costs around Stock Relocations.}

Theory suggests that relationships between crowd members who plan to follow a relocating stock and those who do not begin to break down as the relocation date nears. Theory also suggests that it takes time and multiple interactions for relationships to form between members of the new crowd. In each of these situations, the break-down of relationships creates greater adverse selection problems for liquidity providers in the crowd. Thus, if relationships on the NYSE floor help attenuate adverse selection problems, then we posit that trading costs (effective spreads) increase in the days leading up to a stock's relocation, remain high on the day the stock relocates, and then gradually decline in the days following the stock's relocation.

As theory does not provide guidance as to when the relationships break down or evolve, we begin computing spreads for each relocating stock and its match 50 trading days before and end 50 trading days after the sample stock moves. We then test our hypothesis by examining the difference between the effective spreads of the moving and non-moving stocks through time using standard event study methodology. We include a stock pair (i.e., a relocating stock and its match) in our tests on an event day when the sample and control stock each have two or more trades on the day and each have a trade-weighted average price that equals or exceeds $\$ 5.00$. The price screen decreases the chance that our results are driven by large percentage spreads on low-priced stocks and the trading activity screen increases the reliability of our trading cost estimates. The imposition of these screens on a daily basis, which maximizes the sample size on a given day, implies that the sample size can change from day to day in our estimation period.

\section{A. Relocation and Effective Spreads.}

We begin by plotting the differences in relative effective spreads for sample and control stocks around the sample stocks' relocation on the NYSE floor. For each stock-pair in the sample on a given event day, we subtract the matched stock's share-weighted relative effective spread for the day from the sample stock's share-weighted relative effective spread on the same day. Because theory suggests larger trades are most likely to be affected by disruptions to relationships, we aggregate effective spreads on a stock-day by 
share-weighting effective spreads on individual trades. (Results are qualitatively identical when we tradeweight.) We next find the median difference across all stock-pairs in the sample on that day. These differences are plotted for event day -60 through event day +60 for the entire sample and for the group of relocating stocks with above-median adverse selection costs in Figure 1.

\section{[Insert Figure 1.]}

Figure 1 presents evidence consistent with our hypothesis. We find that relative effective spreads for the entire sample of relocating stocks and their controls are approximately equal in the period of time well before and after the location change. Beginning about 40 to 45 trading days prior to the switch, relative effective spreads for the relocating stocks increase versus their controls. From event day -5 through event day +27 the median (mean) difference is about two (five) basis points. With an average sample stock price of $\$ 26.80$, a five basis point increase in relative effective spreads represents an increase in trading costs of over $\$ 0.01$ per share. Given that the average dollar effective spread is $\$ 0.0704$, this represents an economically significant increase in effective spreads of $19 \%$.

\section{[Insert Table IV.]}

Table IV reports the results of cross-sectional t-tests (Wilcoxon tests) of the mean (median) spread difference between relocating stocks and their controls for event days -55 through $+55 .{ }^{12}$ Consistent with results presented in Figure 1, we find evidence of statistically increased relative effective spreads for relocating stocks versus their controls starting around event day -35 and ending after event day +35 . This suggests that the trading process is disrupted about seven weeks prior to the relocation and that it takes about eight weeks for spreads to return to 'normal' after a location change. Thus, we find evidence consistent with

\footnotetext{
${ }^{12} \mathrm{We}$ anticipate that the change in location causes an increase in spread variance, which will produce atest statistic rejecting the null hypothesis of zero spread differences too frequently (see Brown and Warner, 1980 and 1985). We use the standardized crosssectional test developed by Boehmer, Musumeci, and Poulsen (1991) to solve this problem. Each of the differences that are found to be statistically significant with the standardized cross-sectional test is also found to be significant using the standard t-test. The results reported in the paper use the period from event day -120 through event day -80 as the base period. Similar results obtain when we use the period from event day -100 through event day -50 as the base period and when we use the standard t-test.
} 
an upward dislocation in trading costs in the time before the switch and elevated trading costs afterwards. These results support the hypothesis that reputation effects matter in the trading process.

Theory suggests that the stocks for which relationships are most important are those with high levels of adverse selection. In stocks with little private information, ending or starting a relationship should not matter much. To investigate this intuition, we divide the sample of relocating stocks into two groups based on their level of adverse selection. We measure adverse selection as the difference between the relocating stocks' effective and realized spreads on event days -120 through $-80 .{ }^{13}$ If the effective spread is much larger than the realized spread (i.e., the stock price moves in the liquidity demander's favor post-trade), then we conclude that there is substantial adverse selection. We divide the sample stocks into high and low adverse selection sub-samples by comparing each relocating stock's adverse-selection measure to the median measure.

\section{[Insert Table V.]}

Table V contains descriptive statistics for characteristics of the high and low adverse selection subsamples relative to their matched stocks. Not surprisingly, the high adverse selection sub-sample of relocating stocks has lower stock prices, fewer trades, and fewer shares traded than the overall sample. In addition, we see that the high adverse selection sub-sample of relocating stocks has higher effective spreads and lower realized spreads than their controls.

We repeat the event study for the high adverse selection sub-sample of relocating stocks. Figure 1 graphs the median differences in the stock pair's daily share-weighted relative effective spreads. The preand post-event difference in relative effective spreads is around three basis points. This is not surprising because we rank relocating stocks based on their level of adverse selection well before the start of our event study. Around the switch date, the difference increases to between 10 and 14 basis points. This represents

\footnotetext{
${ }^{13}$ We pick a different period of time than the period of time used to select our control stocks. Using the same period as we use to select control stocks (days -100 through -50) produces nearly identical high/low designations.
} 
an increase in the spread difference of 7 to 11 basis points. The change is greater than the change documented for the overall sample, which is consistent with the claim that reputations matter more for stocks with greater adverse selection. Given the $\$ 17.14$ average share price for the high-adverse-selection sample stocks, a ten basis point increase translates into a 1.7 cent increase in effective spreads. Again, this is economically significant when compared to an eight cent average effective spread. The difference in effective spreads returns to its pre-relocation level by event day +50 .

\section{[Insert Table VI.]}

As with the overall sample, we conduct statistical tests of the daily relative effective spread differences in the period of time surrounding the relocation of stocks with above-median levels of adverse selection and report the results in Table VI. The evidence of widening effective spreads for the high adverse selection sub-sample is more convincing than that for the sample as a whole. With few exceptions, starting 45 days before the switch and continuing 35 days after the switch, the relocating stocks with high adverse selection have relative effective spreads that are higher than their controls each day using at least one of the statistical tests. These results are consistent with the hypothesis that reputations and relationships on the floor of the NYSE are economically meaningful.

\section{[Insert Figure 2.]}

Finally, to address concerns that our results are driven by a few of the six events described in Table I, we plot the differences in relative effective spreads between relocating stocks and their controls for the four largest relocations in our sample in Figure 2. We exclude the two smallest relocations Because the daily estimates of the median effective spread across 11 and 28 stocks are quite noisy. All of the four events (one reallocation, two acquisitions, and one opening of a new floor) leave similar footprints in the data. Benchmarked against their controls, the relative effective spreads of the relocating stocks begin to rise around event day -35 , level off around event day 0 , and begin falling around event day 10 . By event day 40 , there 
is little difference between the relative effective spreads of the relocating stocks and their controls. Figure 2 suggests the results presented in Figure 1, in Table IV, and in Table VI are not driven by one event.

\section{B. Relocation and Realized Spreads.}

We have demonstrated that the trading costs investors pay (the effective spread) increase prior to the sample stocks' relocation and continue at an elevated level for some time afterwards. This is consistent with relationships being important in the trading process. Wenext investigate whether the increase in trading costs paid by investors for immediacy translates into an increase in the trading revenue earned by liquidity providers. We use the realized spread, which compares the trade price to the midpoint of the bid/ask spread five minutes after the trade, as a proxy for gross trading revenue. If a liquidity provider buys (sells) and the stock price falls (rises) during the five minutes following a trade, then the liquidity provider might lose all or part of the effective spread paid by the liquidity demander at the time of the trade. Implicitly, this measure assumes that on average, liquidity providers unwind their positions at the midpoint of the bid/ask spread prevailing five minutes after they trade. An increase in the realized spread around the time of the change in location would suggest that liquidity providers (including the specialist) can retain at least a portion of the increase in effective spreads. Should the realized spread remain constant across the change, however, we would conclude that the increase in effective spreads is just sufficient to offset additional adverse selection costs. Finally, a decrease in realized spreads in the days preceding and immediately following stock relocations would suggest that liquidity providers are harmed by the change in locations.

[Insert Figure 3.]

Figure 3 contains a plot of the daily median difference in the mean relative realized spread (relocating stock minus control) for both the overall sample and the high-adverse-selection sub-sample. We see little change in realized spreads around the relocation date; the realized spread differential seems to fluctuate around zero. This suggests that the increase in effective spreads is approximately sufficient to compensate liquidity providers for the higher levels of adverse selection in the market around location 
changes. Cross-sectional t-tests of the mean and Wilcoxon tests of the median realized spread difference between relocating stocks and their controls for event days -50 through +50 confirm this conclusion (results not reported).

C. Multivariate Analysis of the Differences in Relative Effective Spreads.

Thus far, we have shown that relative effective spreads for relocating stocks rise versus their controls prior to the location change, remain elevated for some time, and then return to 'normal' levels. Consistently with theory, this is particularly true for sample stocks with greater-than-median levels of adverse selection. Realized spreads exhibit no such trend. To determine whether the effective spread result is robust in a multivariate setting, we estimate the following regression equation:

$\Delta \mathrm{ES}_{\mathrm{jt}}=\alpha+\beta_{1}\left(\right.$ High $\left.\mathrm{AS}_{\mathrm{j}}\right)(\text { Event Time })^{2}+\beta_{2}($ Low MB $\mathrm{j})(\text { Event Time })^{2}+\beta_{3}\left(\right.$ AS Costs $\left._{\mathrm{jt}}\right)+$

$\beta_{4}\left(\Delta\right.$ Trade $\left._{\text {Size }} \mathrm{jt}\right)+\beta_{5}\left(\Delta \#\right.$ of $\left.\operatorname{Trades}_{\mathrm{jt}}\right)+\beta_{6}\left(\Delta\right.$ Trade Price $\left.\operatorname{Inv}_{\mathrm{jt}}\right)+\beta_{7}($ New Location Dummy $)+\epsilon_{\mathrm{jt}}$,

where $\Delta \mathrm{ES}_{\mathrm{jt}}$ is the difference in the relative effective spreads for stock-pair $\mathrm{j}$ on event-day $\mathrm{t}, \mathrm{High} \mathrm{AS}_{\mathrm{j}}$ is a binary variable taking the value of 1 if the relocating stock has a higher-than-median level of adverse selection in the control period, (Event Time) ${ }^{2}$ is the event date squared, Low $\mathrm{MB}_{\mathrm{j}}$ is a binary variable taking a value of 1 if the fraction of floor brokers following a stock to its new location is less than the $75^{\text {th }}$ percentile for relocating stocks and zero otherwise, ${ }^{14} \mathrm{AS} \operatorname{Costs}_{\mathrm{jt}}$ is the daily average of the difference between the relocating stock's effective and the realized spreads, $\Delta$ Trade Size $_{\mathrm{jt}}$ is the difference in average trade sizes for stock-pair $\mathrm{j}$ on event-day $\mathrm{t}, \Delta \#$ of $\operatorname{Trades}_{\mathrm{jt}}$ is the difference in the number of trades for stock-pair $\mathrm{j}$ on event-day $\mathrm{t}, \Delta$ Trade Price $\mathrm{Inv}_{\mathrm{jt}}$ is the difference in the inverses of the trade prices for stock-pair $\mathrm{j}$ on event day $t$, and the New Location Dummy is a binary variable taking the value of 1 if event-day $t$ is on or after the

\footnotetext{
${ }^{14} \mathrm{We}$ choose the $75^{\text {th }}$ percentile rather than the median as our break point because over $50 \%$ of the relocating stocks have zero brokers moving to the new location.
} 
relocation date and the value of 0 otherwise. We include fixed effects for each event day in the regression, but we do not report those results.

Theory suggests that the estimates of $\beta_{1}$ and $\beta_{2}$ will be negative - consistent with a larger effect on $\Delta \mathrm{ES}$ (more curvature in the time series of differences in relative effective spreads) for relocating stocks with high adverse selection and few relocating floor brokers. We already have documented the former effect in a univariate setting. We hypothesize that relocating stocks with fewer brokers moving have more of a turnover in the trading crowd, and therefore, have more disruption in the trading process. Trade size, trade price, and the number of trades are control variables. The time series of the relocating stock's adverse selection is included to allow the level of adverse selection to change throughout the event window.

[Insert Table VII.]

Table VII contains the results of our multivariate analysis of the differences in effective spreads around location changes. Each of the control variables is associated with differences in the effective spreads of relocating stocks and their controls. Relative to their controls, relocating stocks have larger effective spreads when they have larger trades than their controls, when they have more trades than their controls, and when they have lower prices than their controls. The difference in effective spreads between moving stocks and their controls is also directly related to the moving stock's level of adverse selection during the event period. Of particular interest, we see that the time series of differences in effective spreads (relocating stocks minus their controls) is more extremely 'humped' for relocating stocks with high levels of adverse selection costs and/or for moving stocks with few relocating floor brokers. We obtain similar results when the two factors are considered separately (models 1 and 2), together (model 3), or together with an additional post switch binary variable (model 4). These results are consistent with the hypothesis that reputations are useful in countering the adverse selection problem on the floor of the NYSE. 


\section{Summary.}

We find that disruptions to relationships on the NYSE floor are associated with increases in trading costs. Relative to a matched sample of stocks that do not change location, our relocating stocks' effective spreads increase in the six to eight weeks prior to their move and remain elevated for several weeks after the move. This increase in effective spreads is evident in both univariate and multivariate analyses. We hypothesize that this dislocation is due to disruptions in trading relationships. Consistent with theory, we also find that the increase in trading costs is positively related to the adverse selection of the relocating stock and is inversely related to the fraction of brokers that relocate with the moving stock.

\section{Analyses using Consolidated Audit-Trail Data.}

The NYSE's Consolidated Audit Trail Data allow us to examine the apparent effects of a change in trading location on the NYSE in greater detail. Because we have floor broker badge numbers, we can study the trading behavior of individual traders. We examine the trading behavior of brokers moving with the specialist to the new location, brokers not moving (in the pre-move period), and brokers that begin trading with the specialist in the post-move period. We also compute trading costs associated with trades between parties who maintain a relationship and parties who have their relationship interrupted or establish a new relationship. We expect that trades between the specialist and a floor broker that occur after a stock relocates might enjoy lower trading costs when the specialist and the floor broker have had face-to-face interactions in the past. It also is possible that floor brokers treat each other differently after the move. Trades between relocating brokers might enjoy a level of comfort (i.e., a relationship) not evident when a relocating broker trades with a new (i.e., non-moving) broker.

\section{[Insert Table VIII.]}

In Table VIII, we provide the across-stock average daily trading volume and trade size for selected periods of time before and after the stock relocates on the floor of the NYSE for brokers moving with the 
stock and for brokers not moving with the stock. We equally-weight each sample stock. We find that the day before the stock moves has the lowest volume and the smallest average trade size. This is consistent with the claim that brokers modify their trading behavior anticipating being taken advantage of just prior to the disruption in relationships.

If relationships matter, then trades involving moving brokers after stocks relocate should have less price impact than trades involving brokers who did not relocate. To examine this, we estimate the following equation using ordinary least squares:

$\left|\frac{\Delta \text { PRCE }}{\text { PRCE }}\right|=\alpha+\beta($ TRADE QUANTITY $)+\gamma($ MOVING BROKER DUMMY $)+\delta($ HIGH AS DUMMY $)+\varepsilon$,

where $\triangle P R I C E$ is the price of the trade of interest less the previous trade price (from CAUD), PRICE is the transaction price of the trade of interest, TRADE QUANTITY is the number of shares the broker trades in the trade of interest, MOVING BROKER DUMMY is a binary variable taking a value of 1 if the broker involved in the trade transacts in the stock both before and after the move and a value of 0 otherwise, and $H I G H A S$ $D U M M Y$ is a binary variable taking a value of 1 if the stock in the trade of interest has a higher-than-median level of adverse selection and a value of 0 otherwise. ${ }^{15}$ Given our estimates and a hypothetical 10,000 share trade, we find that on average, a non-moving broker trading a low adverse selection stock has a price impact of 12 basis points (our estimate of $\alpha$ is 0.00106 and our estimate of $\beta$ is 0.000000047 ). For trades in relocating stocks with high levels of adverse selection, the average price impact for non-movers doubles (our estimate of $\delta$ is 0.00121 ). Finally, trades handled by moving brokers have five basis points less price impact (our estimate of $\gamma$ is -0.00049 ) on average. These results are consistent with the claim that relocating brokers use their reputations to lessen the price impact of their trades.

\footnotetext{
0.0001 level.

${ }^{15}$ We estimate this model with 2,319,198 observations and find that each of the coefficient estimates is significant at the
} 
To examine the cost of trading incurred by moving and non-moving brokers, we use CAUD to identify trades in which a floor broker transacts with either the specialist or another floor broker. We then determine whether the floor broker(s) involved in the trade follow the specialist to the new location or if the broker(s) are non-mover(s). Prior to the relocation, non-moving brokers are brokers who cease to trade the stock after the move. Following the relocation, many floor brokers are new to the trading crowd and must initiate new relationships. For simplicity in exposition, we also refer to these new brokers as non-moving brokers. When both counter-parties are floor brokers, we distinguish between trades in which both parties are moving brokers and those trades in which one broker is a mover and the other a non-mover. Because Table VIII suggests that there are differences between the types of trades of moving and non-moving brokers, we limit our univariate analysis to stock-days on which both moving and non-moving brokers trade a given stock.

\section{[Insert Table IX.]}

We report the results of a statistical test for differences in the median share-weighted effective spreads for trades involving moving and non-moving brokers in Table IX. Comparing the median effective spreads that movers and non-movers pay when trading with the specialist in Panel A reveals that non-moving brokers pay higher effective spreads for most days in the pre-move period (statistically so for days $-8,-5$, and -1 ) and consistently in the four days following the relocation. The wider gap between movers' and non-movers' spreads is due to an increase in the non-movers' spread around the event day. Movers' spread remain relatively constant (five-day averages of the movers' median spreads is $22-23$ basis points). This result is consistent with the hypothesis that relocating brokers receive better trade prices from specialists than nonmoving brokers and that relationship is disrupted by the move.

Finally, we examine the effective spreads in trades between floor brokers around a stock's relocation. Although the Exchange monitors specialists regardless of where they trade on the floor, it is possible that the relocation disrupts floor brokers' ability to evaluate specialists and/or, in the specialist firm merger subsample, makes it temporarily unclear which specialist firm (bidder or target) is required to monitor the 
specialist. If there is sufficient disruption in specialist monitoring, then specialists might try to gain an advantage when taking one side of the trade. This should not, however, affect trades between floor brokers. ${ }^{16}$ In Panel B of Table IX, we examine trades between floor brokers. There is evidence that trades involving two moving brokers have lower trading costs than trades involving one mover and one non-mover beginning seven days prior to the move (except for day -2). On eight of the ten pre-move days, trades between movers have lower effective spreads (significantly so on event days $-7,-5,-4$, and -2 ). Afterwards, the floor community knows who moved with the stock and who is new. In other words, a relocating broker knows whether she is trading with someone whom she is familiar with or not. We find that after stocks relocate, trades between two moving brokers have lower effective spreads than trades between unfamiliar floor brokers for five of the first six post-move trading days (significantly so on day $+1,+2$, and +5 ). Averaging the daily medians, we find that the movers' effective spreads are lowest in the period of time from event day -5 through event day +5 . These results provide more empirical evidence that reputations matter even if the specialist is not involved in the trade.

Because moving and non-moving brokers have different characteristics in the pre-move period (e.g., moving brokers' average trade size is about twice non-movers), we question whether the univariate analysis presented in Table IX (despite conditioning) might simply reflect differences in stock characteristics. To investigate this issue further, we conduct a multivariate analysis. Our goal is to understand the extent to which relationships amongst floor brokers and between floor brokers and the specialist help to attenuate the adverse selection problem faced by liquidity providers on the floor of the NYSE. Thus, we wish to explain the effective spread of trades between floor brokers and specialists conditional on whether the floor broker follows the specialist to the stock's new trading location. Market microstructure theory suggests that we should control for trade size, share price, and trading activity when trying to explain effective spreads. In addition, we distinguish between stocks with above-median levels of adverse selection and those with below-

\footnotetext{
${ }^{16}$ We thank Larry Harris for suggesting this.
} 
median levels. We also posit two time effects: one to distinguish the pre- and the post-move periods and another to allow for a heightened difference close to the move date. Specifically, we estimate the following regression:

$$
\begin{aligned}
\text { ES }= & \alpha+\beta_{1}(\text { Moving Broker })+\beta_{2}(\text { Moving Broker })(\text { Event Time })^{2}+\beta_{3}(\text { Moving Broker })(\text { High AS })+ \\
& \beta_{4}(\text { Moving Broker })(\text { New Location Dummy })+\beta_{5}(\text { High AS })+\beta_{6}(\text { Trade Size })+\beta_{7}(\text { Trade Price Inv })+ \\
& \beta_{8}(\# \text { of Trades })+\beta_{9}(\text { New Location Dummy })+\epsilon
\end{aligned}
$$

where ES is the effective spread of the trade of interest, Moving Broker is a binary variable taking a value of one if the broker associated with the trade of interest moves with the specialist and a value of zero otherwise, High AS is a binary variable taking a value of one if the stock being traded has higher-than-median adverse selection costs and a value of zero otherwise, New Location Dummy is a binary variable taking a value of one if the trade occurs after the stock has relocated and a value of zero otherwise, Trade Size is the size of the trade in shares, Trade Price Inv is the inverse of the transaction price, and \# of Trades is the number of trades in the stock-day of interest. We expect that trades facilitated by moving brokers will have lower costs (i.e., $\beta_{1}<0$ ). Because we expect that relationships are more important when trading stocks with above-median levels of adverse selection, we interact the Moving Broker and the High AS variables and expect that $\beta_{3}<0$. We interact the Moving Broker variable with event date squared to allow for a non-linear trend in effective spreads around the change in location. If concerns about adverse selection increase just prior to the move and if time is required for the specialist to become familiar with new traders after the move, then we expect the trading cost advantage moving brokers enjoy over non-moving brokers to diminish over time (i.e., $\beta_{2}>0$ ). We allow for a discontinuity in the association between moving brokers and the effective spreads by interacting the moving broker and the new location dummy variables. Finally, all else equal, we expect that effective spreads are higher for trades that are large, for trades in low priced stocks, for trades in low volume stocks, 
and for trades in stocks with high adverse selection costs. We include all trades involving a floor broker as one party and either another floor broker or a specialist as the counter-party in the regression.

\section{[Insert Table X.]}

As expected, large trades and trades with a low share price have higher effective spreads than small trades and trades in higher priced stocks (i.e., both $\beta_{6}$ and $\beta_{7}$ are greater than zero). Trades in stocks with high adverse selection tend to have higher effective spreads than trades in stocks with lower levels of adverse selection, but the overall difference is not significant. Turning to the variable of interest, we find that moving brokers enjoy significantly lower (statistically and economically) effective spreads than non-moving brokers when we differentiate the pre- and post-move periods. This advantage is particularly strong in stocks where the adverse selection problem is more severe. For high adverse selection stocks, moving brokers trade with effective spreads that are 16 basis points $\left(\beta_{1}+\beta_{3}+\beta_{4}\right)$ less than non-movers on the event date. For a $\$ 15.00$ stock, this translates into a cost advantage of $\$ 0.024$. As we move further away from the event day in either direction, the advantage enjoyed by the moving brokers dissipates $\left(\beta_{2}\right.$ is positive). This is consistent with the idea that specialists become more concerned about end-game problems in the pre-move period and gradually learn the trading styles of new brokers after they relocate. If the trend we identify in the ten post-move days of CAUD data we analyze continues, then the advantage relocating brokers enjoy over new brokers in stocks with above-median levels of adverse selection vanishes about 21 days after the move. Moving brokers have no advantage over new brokers in trading stocks with below-median levels of adverse selection after a stock relocates (i.e., $\beta_{4}$ is approximately equal to $\beta_{1}$ in absolute value). Thus, we conclude that relocating brokers enjoy lower trading costs than brokers that do not follow stocks with high levels of adverse selection to their new locations even when we control for other factors known to influence effective spreads. This is yet more evidence suggesting reputations play a role in the trading process on the floor of the NYSE. 


\section{Conclusion.}

This paper explores whether relationships on the floor of the NYSE play an economically important role in the trading process. To test this hypothesis, we identify instances in which stocks change trading locations (move to different rooms) on the NYSE floor for exogenous reasons. For the relocations we study, the specialist and the set of stocks are held constant but the floor community changes dramatically. We find an economically and statistically meaningful increase in trading costs as measured by relative effective spreads in the days leading up to and following the relocation of stocks on the NYSE floor versus a matched sample of stocks that do not move. This effect is strongest for stocks where the adverse selection problem is most severe. This result suggests that relationships on the floor of the NYSE are economically important.

Using proprietary consolidated audit trail data from the NYSE, we document more direct evidence that the floor of the NYSE fosters relationships that help to overcome the adverse selection problems inherent in equity trading. Specifically, we find that floor brokers that maintain their relationship with the specialist when a set of stocks relocate between rooms on the floor of the NYSE obtain better execution prices than the floor brokers that terminate relationships when stocks leave their old location or begin relationships when stocks trade at their new location. Finally, we find that trades involving a moving and a non-moving floor broker that occur after a stock changes its location have higher effective spreads than similar trades between floor brokers that followed the stock to its new location. Together, these results suggest that reputations nurtured on the floor of the NYSE play an economically important role in the trading process. More generally, these results provide an economic justification for floor-based exchanges.

Whether the advantages to non-anonymous trading are sufficient to overcome the cost advantages of electronic trading is an empirical question. Even for stocks with relatively high levels of adverse selection, we find that effective spreads increase by little more than ten basis points in the days surround a stock's relocation. It is possible that the efficiency of electronic exchanges more than offsets this difference. Conversely, our estimates of the advantage of repeated interactions on the floor of the NYSE may understate 
the economic benefit. On the NYSE, the specialist's obligation to provide liquidity does not change when a stock relocates. Because we estimate the value of relationships in a constrained environment, our estimates may not fully capture the value of face-to-face trading in markets without constraints. 


\section{References}

Akerloff, George, 1970, The market for lemons: Quality uncertainty and the market mechanism, Quarterly Journal of Economics 84, 488-500.

Bacidore, Jeffery and George Sofianos, 2002, Liquidity provision and specialist trading in NYSE-listed NonU.S. stocks, Journal of Financial Economics 63, 133-158.

Baker, Wayne and Ananth Iyer, 1992, Information networks and market behavior, Journal of Mathematical Sociology 15, 305-332.

Barclay, Michael, Terrence Hendershott and D. Timothy McCormick, 2003, Competition among trading venues: Information and trading on electronic communications networks, Journal of Finance 58, 2639-2667.

Benveniste, Lawrence, Alan Marcus and William Wilhelm, 1992, What's so special about the specialist?, Journal of Financial Economics 32, 61-86.

Bessembinder, Hendrik and Herbert Kaufman, 1997, A cross-exchange comparison of execution costs and information flow for NYSE-listed stocks, Journal of Financial Economics 46, 293-319.

Bessembinder, Hendrik and Kumar Venkataraman, 2004, Does an electronic stock exchange need an upstairs market?, Journal of Financial Economics 73, 3-36.

Boehmer, Ekkehart, Jim Musumeci and Annette Poulsen, 1991, Event-study methodology under conditions of event-induced variance, Journal of Financial Economics 30, 253-272.

Boehmer, Ekkehart, Gideon Saar and Lei Yu, 2004, Lifting the veil: An analysis of pre-trade transparency at the NYSE, Journal of Finance, forthcoming.

Boot, Arnoud, Stuart Greenbaum and Anjan Thakor, 1993, Reputation and discretion in financial contracting, American Economic Review 83, 1165-1183.

Brennan, Michael and Avanidhar Subrahmanyam, 1996, Market microstructure and asset pricing: On the compensation for illiquidity in stock returns, Journal of Financial Economics 38, 361-382.

Brown, Stephen and Jerold Warner, 1980, Measuring security price performance, Journal of Financial Economics 8, 205-258.

Brown, Stephen and Jerold Warner, 1985, Using daily stock returns: The case of event studies, Journal of Financial Economics 14, 3-31.

Cao, Charles, Hyuk Choe and Frank Hatheway, 1997, Does the specialist matter? Differential execution costs and inter-security subsidization on the NYSE, Journal of Finance 52, 1615-1640.

Carlin, B., M. Lobo and S. Viswanathan, 2004, Episodic Liquidity Crises: The Effect of Predatory and Cooperative Trading, Working Paper, Duke University. 
Carter, Richard and Steven Manaster, 1990, Initial public offerings and underwriter reputation, Journal of Finance 45, 1045-1067.

Chakravarty, Sugato, 2002, Stealth-trading: Which traders' trades move stock prices?, Journal of Financial Economics 61, 289-307.

Chan, Yuk-Shee and Mark Weinstein, 1993, Bid-ask spread and market structure, Financial Analysts Journal, 57-62.

Cohen, Randolph, 2003, Dimensional Fund Advisors - 2002, Harvard Business School Case No. 9-203-026, Harvard Business School Publishing, Boston, Mass.

Corwin, Shane, 1999, Differences in trading behavior across NYSE specialist firms, Journal of Finance 54, 721-745.

Corwin, Shane and Marc Lipson, 2000, Order flow and liquidity around NYSE trading halts, Journal of Finance 55,1771-1801.

Coughenour, Jay and Mohsen Saad, 2004, Common market makers and commonality in liquidity, Journal of Financial Economics 73, 37-69.

Coval, Joshua and Tyler Shumway, 2001, Is sound just noise?, Journal of Finance 56, 1887-1910.

DeJong, Douglas, Robert Forsythe and Russell Lundholm, 1985, Ripoffs, lemons, and reputation formation in agency relationships: A laboratory market study, Journal of Finance, 40, 809-820.

Dellarocas, Chrysanthos, 2004, The digitization of word-of-mouth: Promises and challenges of online feedback, Working Paper, Massachusetts Institute of Technology.

Desgranges, Gabriel, and Thierry Foucault, 2005, Reputation-based pricing and price improvements in dealership markets, Working Paper, University of Cergy.

Diamond, Doug, 1989, Reputation in debt markets, Journal of the Political Economy 97, 828-862.

Diamond, Doug, 1991, Monitoring and reputation: The choice between bank loans and directly placed debt, Journal of Political Economy 99, 689-721.

Finucane, Thomas, 2000, A direct test of methods for inferring trade direction from intra-day data, Journal of Financial and Quantitative Analysis 35, 553-576.

Garfinkel, Jon and Mahendrarajah Nimalendran, 2003, Market structure and trader anonymity: An analysis of insider trades, Journal of Financial and Quantitative Analysis 38, 591-610.

Granovetter, Mark, 1985, Economic action and social structure: The problem of embeddedness, The American Journal of Sociology 91, 481-510.

Handa, Puneet, Robert Schwartz and Ashish Tiwari, 2004, The economic value of a trading floor: Evidence from the American Stock Exchange, Journal of Business 77, 331-355. 
Huang, Roger and Hans Stoll, 1996, Dealer versus auction markets: A paired comparison of execution costs on Nasdaq and the NYSE, Journal of Financial Economics 41, 313-357.

Huang, Roger and Hans Stoll, 1997, The components of the bid-ask spread: A general approach, Review of Financial Studies 10, 995-1034.

Klein, Daniel, ed., 1997, Reputation: Studies in the voluntary elicitation of good conduct, Ann Arbor: University of Michigan Press.

Kyle, Albert, 1985, Continuous auctions and insider trading, Econometrica 53, 1315-1336.

Lee, Charles and Balkrishna Radhakrishna, 2000, Inferring investor behavior: Evidence from TORQ data, Journal of Financial Markets 3, 183-204.

Lee, Charles and Mark Ready, 1991, Inferring trade direction from intraday data, Journal of Finance 46, 733746.

Madhavan, Ananth and Venkatesh Panchapagesan, 2000, Price discovery in auction markets: A look inside the black box, Review of Financial Studies 13, 627-658.

Odders-White, Elizabeth, 2000, On the occurrence and consequences of inaccurate trade classification, Journal of Financial Markets 3, 259-286.

Pagano, Marco and Ailsa Roell, 1992, Auction and dealership markets: What is the difference?, European Economic Review 36, 613-623.

Sofianos, George and Ingrid Werner, 2000, The trades of NYSE floor brokers, Journal of Financial Markets 3, 139-176.

Stoll, Hans, 2000, Friction, Journal of Finance 55, 1479-1514.

Theissen, Eric, 2000, Market structure, informational efficiency and liquidity: An experimental comparison of auction and dealer markets, Journal of Financial Markets 3, 333-363.

Venkataraman, Kumar, 2001, Automated versus floor trading: An analysis of execution costs on the Paris and New York Stock Exchanges, Journal of Finance 56, 1445-1485.

Waisburd, Andrew, 2003, Anonymity and liquidity: Evidence from the Paris Bourse, Working Paper, Neeley School of Business, Texas Christian University.

Wilner, Benjamin, 2000, The exploitation of relationships in financial distress: The case of trade credit, Journal of Finance 55, 153-178. 


\section{Table I}

\section{Descriptive Statistics for Relocating Stocks}

On the dates listed below, the indicated number of stocks changed the location at which they trade on the floor of the NYSE. The move involves the entire panel of stocks moving to a new room on the floor and continuing to trade as one panel. The apparent reason for the relocation is indicated. Our data cover the period from July 1999 through April 2003.

\begin{tabular}{lcl} 
Date & $\begin{array}{c}\text { Number of } \\
\text { Relocating Stocks }\end{array}$ & Apparent Reason for Relocation \\
\hline July 28, 1999 & 11 & Internal reallocation by Fleet \\
June 1, 2000 & 100 & $\begin{array}{l}\text { Internal reallocations by LaBranche, Fleet, and } \\
\text { Susquehanna }\end{array}$ \\
November 20, 2000 & 410 & Opening of new trading floor at 30 Broad Street \\
December 11, 2000 & 380 & Spear Leeds acquires Benjamin Jacobson \\
December 20, 2000 & 167 & Fleet acquires Meehan \\
March 25, 2002 & 28 & $\begin{array}{l}\text { Internal reallocations by Performance, Susquehanna, and } \\
\text { Van Der Moolen }\end{array}$ \\
\hline
\end{tabular}


Table II

\section{Descriptive Statistics for Floor Broker Trading Around Stock Relocations}

We examine the trading associated with unique broker badge numbers in the NYSE's audit file in the days immediately prior to and the days immediately following the change in location to create the statistics provided in the table. We have uninterrupted data for two weeks before and two weeks after the relocation (i.e., event days -10 through +10 ) and we have data for event days -15 and -20 .

Panel A. Floor broker trading in relocating stocks.

Mean number of floor brokers trading in a sample stock prior to the relocation:

Percentage of relocating stocks in which a floor broker makes at least one trade prior to the relocation:

$89.16 \%$

Mean number of floor brokers trading in a sample stock prior to the relocation conditional on there being floor broker trading activity in the stock prior to the move:

Percentage of floor brokers moving with the specialist to the new trading location:

Percentage of trades executed prior to the move associated with relocating brokers:

Percentage of shares executed prior to the move associated with relocating brokers:

$6.32 \%$

Panel B. Characteristics of floor broker trading activity.

\begin{tabular}{lcc}
\hline & $\begin{array}{c}\text { Relocating } \\
\text { Brokers }\end{array}$ & $\begin{array}{c}\text { Non-Relocating } \\
\text { Brokers }\end{array}$ \\
\hline $\begin{array}{l}\text { Mean number of panels at which the floor broker trades } \\
\text { before the stock relocates: }\end{array}$ & 1.68 & 3.08 \\
$\begin{array}{l}\text { Median number of panels at which the floor broker trades } \\
\text { before a stock relocates: }\end{array}$ & 1.00 & 2.00 \\
$\begin{array}{l}\text { Maximum number of panels at which the floor broker trades } \\
\text { before a stock relocates: }\end{array}$ & 8.00 & 16.00 \\
$\begin{array}{l}\text { Percentage of floor broker badge numbers with trades at only } \\
\text { one panel before a stock relocates: }\end{array}$ & $50 \%$ & $10 \%$ \\
\hline
\end{tabular}


Table III

Descriptive Microstructure Statistics for Relocating and Matched Control Stocks

The sample stocks changed the room on the floor of the NYSE in which they trade between July 1999 and April 2003. An entire panel of stocks made the switch and continued to trade as a panel after the relocation. Each sample stock is matched with a non-moving stock on the basis of market capitalization, share price, trading volume, and share price volatility. The statistics provided below are estimated using data from event day -100 through event day -50 . We characterize the distribution of daily averages of various microstructure statistics for both relocating and for matched stocks below.

\begin{tabular}{|c|c|c|c|c|c|c|}
\hline & & Mean & Median & Std. Dev & Minimum & Maximum \\
\hline \multirow{2}{*}{$\begin{array}{l}\text { Trade-Weighted } \\
\text { Average Price }\end{array}$} & Sample & $\$ 26.80$ & $\$ 22.41$ & $\$ 20.13$ & $\$ 5.00$ & $\$ 195.53$ \\
\hline & Control & $\$ 26.22$ & $\$ 22.60$ & $\$ 18.03$ & $\$ 5.00$ & $\$ 181.04$ \\
\hline \multirow{2}{*}{$\begin{array}{l}\text { Share-Weighted } \\
\text { Average Price }\end{array}$} & Sample & $\$ 26.80$ & $\$ 22.41$ & $\$ 20.13$ & $\$ 5.00$ & $\$ 195.56$ \\
\hline & Control & $\$ 26.22$ & $\$ 22.60$ & $\$ 18.02$ & $\$ 5.00$ & $\$ 180.84$ \\
\hline \multirow{2}{*}{$\begin{array}{l}\text { Average \# of } \\
\text { Trades Per Day }\end{array}$} & Sample & 156 & 41 & 310 & 2 & 3,612 \\
\hline & Control & 150 & 41 & 287 & 2 & 3,908 \\
\hline \multirow{2}{*}{$\begin{array}{c}\text { Average \# of Shares } \\
\text { Traded Per Day }\end{array}$} & Sample & 342,471 & 47,000 & $1,137,852$ & 200 & $83,995,400$ \\
\hline & Control & 334,418 & 49,500 & 914,421 & 200 & $24,106,600$ \\
\hline \multirow{2}{*}{$\begin{array}{l}\text { Trade-Weighted } \\
\text { Effective Spread }\end{array}$} & Sample & $\$ 0.0603$ & $\$ 0.0463$ & $\$ 0.0566$ & $\$ 0.0000$ & $\$ 2.7251$ \\
\hline & Control & $\$ 0.0598$ & $\$ 0.0456$ & $\$ 0.0488$ & $\$ 0.0000$ & $\$ 2.3851$ \\
\hline \multirow{2}{*}{$\begin{array}{l}\text { Trade-Weighted } \\
\text { Realized Spread }\end{array}$} & Sample & $\$ 0.0226$ & $\$ 0.0187$ & $\$ 0.0516$ & $-\$ 1.4848$ & $\$ 3.2210$ \\
\hline & Control & $\$ 0.0231$ & $\$ 0.0194$ & $\$ 0.0459$ & $-\$ 0.9268$ & $\$ 4.0169$ \\
\hline \multirow{2}{*}{$\begin{array}{l}\text { Share-Weighted } \\
\text { Effective Spread }\end{array}$} & Sample & $\$ 0.0704$ & $\$ 0.0550$ & $\$ 0.0644$ & $\$ 0.0000$ & $\$ 2.7563$ \\
\hline & Control & $\$ 0.0700$ & $\$ 0.0545$ & $\$ 0.0578$ & $\$ 0.0000$ & $\$ 2.2109$ \\
\hline \multirow{2}{*}{$\begin{array}{l}\text { Share-Weighted } \\
\text { Realized Spread }\end{array}$} & Sample & $\$ 0.0219$ & $\$ 0.0174$ & $\$ 0.0604$ & $-\$ 3.4223$ & $\$ 3.2375$ \\
\hline & Control & $\$ 0.0216$ & $\$ 0.0177$ & $\$ 0.0515$ & $-\$ 1.6672$ & $\$ 4.0495$ \\
\hline
\end{tabular}


Table IV

\section{Differences in the Share-Weighted Relative Effective Spreads of Relocating Stocks and Their Controls}

Control stocks are selected based on market capitalization, share price, trading volume, and stock price volatility. To compute the reported number, we take the difference between the average share-weighted relative effective spread of the stock moving to a new location and the corresponding control stock that does not relocate. Sample stocks relocate on event day 0 . The statistical test for the mean difference being positive is conducted using the Boehmer, Musumeci, and Poulsen (1991) t-statistic with the period - 120 to -80 as the base period. Each of the differences that are found to be statistically significant with the standardized cross-sectional test is also found to be significant using the standard t-test. We use the Wilcoxon test to examine the differences in medians.

\begin{tabular}{|c|c|c|c|c|c|}
\hline \multirow{2}{*}{$\begin{array}{c}\text { Event Time } \\
\text { (days) }\end{array}$} & \multicolumn{2}{|c|}{ Difference in Basis Points } & \multirow{2}{*}{$\begin{array}{c}\text { Event Time } \\
\text { (days) }\end{array}$} & \multicolumn{2}{|c|}{ Difference in Basis Points } \\
\hline & Mean & Median & & Mean & Median \\
\hline-55 & $2.43 *$ & $0.57 *$ & 0 & $6.05 *$ & $2.60 * *$ \\
\hline-45 & 1.38 & 0.38 & 1 & $5.87 *$ & $2.57 * *$ \\
\hline-35 & $3.58 * *$ & $1.39 *$ & 2 & 4.58 & $3.01 * *$ \\
\hline-25 & $3.65 * *$ & $1.12 *$ & 3 & $6.63 * *$ & $3.00 * *$ \\
\hline-20 & 1.00 & $1.06^{*}$ & 4 & $6.00 * *$ & $2.20 * *$ \\
\hline-19 & $2.81 * *$ & $1.49 *$ & 5 & $5.30 * *$ & 1.83 \\
\hline-18 & $4.19 * *$ & $2.29 *$ & 6 & $5.37 * *$ & $3.08 * *$ \\
\hline-17 & $3.23 * *$ & $1.45^{*}$ & 7 & $4.62 * *$ & $3.00 * *$ \\
\hline-16 & $4.42 * *$ & $1.69 *$ & 8 & 5.50 & $3.07 * *$ \\
\hline-15 & $5.39 * *$ & $1.74 *$ & 9 & $4.97 * *$ & $2.61 * *$ \\
\hline-14 & $4.12 * *$ & $2.39 * *$ & 10 & $4.63 * *$ & $1.65^{*}$ \\
\hline-13 & $4.57 * *$ & $2.49 * *$ & 11 & $3.85^{* *}$ & 1.34 \\
\hline-12 & $3.89 * *$ & $1.50 *$ & 12 & $6.96 * *$ & $1.96^{*}$ \\
\hline-11 & 2.99 & 1.05 & 13 & $3.96 * *$ & $2.80 *$ \\
\hline-10 & $4.17 * *$ & $1.92 *$ & 14 & $6.43^{* *}$ & $2.37^{*}$ \\
\hline-9 & $3.65 * *$ & $1.80^{*}$ & 15 & $4.65 * *$ & $1.92 *$ \\
\hline-8 & $3.93 *$ & $1.71 *$ & 16 & 4.34 & $2.29 *$ \\
\hline-7 & $4.52 *$ & 1.42 & 17 & $5.26 * *$ & $2.47 * *$ \\
\hline-6 & $3.66^{* *}$ & $1.62 *$ & 18 & $4.86^{* *}$ & $2.15^{* *}$ \\
\hline-5 & $4.10 * *$ & $2.11 * *$ & 19 & $4.97 *$ & $1.94 *$ \\
\hline-4 & 4.53 & $2.46^{* *}$ & 20 & $7.10 * *$ & $2.97 *$ \\
\hline-3 & $6.81 * *$ & $2.68 * *$ & 35 & $4.45^{*}$ & $1.40^{*}$ \\
\hline-2 & $4.41 * *$ & $1.28 *$ & 45 & $2.90 *$ & 0.67 \\
\hline-1 & 7.84 & $2.36 * *$ & 55 & 1.92 & -0.92 \\
\hline
\end{tabular}

* The difference is statistically significant at the .95 confidence level.

** The difference is statistically significant at the .99 confidence level. 


\section{Table V}

Descriptive Microstructure Statistics for Relocating with High Adverse Selection and Their Controls

The sample stocks changed the room on the floor of the NYSE in which they trade between July 1999 and April 2003. An entire panel of stocks made the switch and continued to trade as a panel after the relocation. Each sample stock is matched with a non-moving stock on the basis of market capitalization, share price, trading volume, and share price volatility. Adverse selection is measured as the difference between the sample stocks' effective and realized spreads on event days -120 through -80 . Our sample of high adverse selection stocks is comprised of relocating stocks with higher than the median level of adverse selection. The statistics provided below are estimated using data from event day -100 through event day -50 . We characterize the distribution of daily averages of various microstructure statistics for both relocating and for matched stocks below.

\begin{tabular}{ccccccc}
\hline & & Mean & Median & Std. Dev & Minimum & Maximum \\
\hline $\begin{array}{c}\text { Trade-Weighted } \\
\text { Average Price }\end{array}$ & Sample & $\$ 17.14$ & $\$ 14.57$ & $\$ 10.92$ & $\$ 5.00$ & $\$ 145.95$ \\
Control & $\$ 17.36$ & $\$ 14.71$ & $\$ 10.62$ & $\$ 5.00$ & $\$ 114.22$ \\
$\begin{array}{c}\text { Share-Weighted } \\
\text { Average Price }\end{array}$ & Sample & $\$ 17.14$ & $\$ 14.57$ & $\$ 10.92$ & $\$ 5.00$ & $\$ 145.66$ \\
Control & $\$ 17.35$ & $\$ 14.70$ & $\$ 10.60$ & $\$ 5.00$ & $\$ 114.22$ \\
Average \# of & Sample & 32 & 12 & 66 & 2 & 1,943 \\
Trades Per Day & Control & 30 & 12 & 63 & 2 & 1,982 \\
Average \# of Shares & Sample & 70,087 & 11,200 & 254,008 & 200 & $7,278,300$ \\
Traded Per Day & Control & 65,465 & 12,200 & 225,947 & 100 & $13,718,300$ \\
Trade-Weighted & Sample & $\$ 0.0715$ & $\$ 0.0553$ & $\$ 0.0654$ & $\$ 0.0000$ & $\$ 2.7251$ \\
Effective Spread & Control & $\$ 0.0669$ & $\$ 0.0497$ & $\$ 0.0598$ & $\$ 0.0000$ & $\$ 2.3851$ \\
Trade-Weighted & Sample & $\$ 0.0252$ & $\$ 0.0210$ & $\$ 0.0590$ & $-\$ 1.1650$ & $\$ 3.2210$ \\
Realized Spread & Control & $\$ 0.0288$ & $\$ 0.0243$ & $\$ 0.0608$ & $-\$ 0.9268$ & $\$ 4.0169$ \\
$\begin{array}{c}\text { Share-Weighted } \\
\text { Effective Spread }\end{array}$ & Sample & $\$ 0.0814$ & $\$ 0.0625$ & $\$ 0.0739$ & $\$ 0.0000$ & $\$ 2.7562$ \\
$\begin{array}{c}\text { Control } \\
\text { Realized Spread }\end{array}$ & $\$ 0.0755$ & $\$ 0.0565$ & $\$ 0.0681$ & $\$ 0.0000$ & $\$ 2.2109$ \\
\hline
\end{tabular}




\section{Table VI}

Differences in the Share-Weighted Relative Effective Spreads of Relocating Stocks with High Adverse Selection and Their Controls

Control stocks are selected based on market capitalization, share price, trading volume, and stock price volatility. To compute the reported number, we take the difference between the average share-weighted relative effective spread of the stock moving to a new location and the corresponding control stock that does not relocate. Sample stocks relocate on event day 0. Adverse selection is measured as the difference between the sample stocks' effective and realized spreads on event days -120 through -80 . Our sample of high adverse selection stocks is comprised of relocating stocks with higher than the median level of adverse selection. The statistical test for the mean difference being positive is conducted using the Boehmer, Musumeci, and Poulsen (1991) t-statistic with the period -120 to -80 as the base period. Each of the differences that are found to be statistically significant with the standardized cross-sectional test is also found to be significant using the standard t-test. We use the Wilcoxon test to examine the differences in medians.

\begin{tabular}{|c|c|c|c|c|c|}
\hline \multirow{2}{*}{$\begin{array}{c}\text { Event Time } \\
\text { (days) }\end{array}$} & \multicolumn{2}{|c|}{ Difference in Basis Points } & \multirow{2}{*}{$\begin{array}{c}\text { Event Time } \\
\text { (days) }\end{array}$} & \multicolumn{2}{|c|}{ Difference in Basis Points } \\
\hline & Mean & Median & & Mean & Median \\
\hline-55 & 6.70 & 6.35 & 0 & $17.73 * *$ & $10.53 * *$ \\
\hline-45 & $7.59 *$ & $5.39 *$ & 1 & $13.08^{*}$ & $10.08 * *$ \\
\hline-35 & $9.65 * *$ & $7.93 *$ & 2 & 11.77 & $12.82 * *$ \\
\hline-25 & $12.75^{*}$ & $8.48^{*}$ & 3 & $16.53^{* *}$ & $11.21^{* *}$ \\
\hline-20 & $9.15^{* *}$ & $8.55^{*}$ & 4 & $15.55^{*}$ & $10.19^{* *}$ \\
\hline-19 & $10.96^{* *}$ & 7.46 & 5 & $14.67 * *$ & $10.59 * *$ \\
\hline-18 & $13.13 * *$ & $11.59 * *$ & 6 & $15.17 * *$ & $11.20 * *$ \\
\hline-17 & $9.44 * *$ & 8.72 & 7 & $13.63 * *$ & $11.16^{* *}$ \\
\hline-16 & $11.92 * *$ & $9.93 *$ & 8 & 11.08 & $13.22 * *$ \\
\hline-15 & $12.24 *$ & $9.58 *$ & 9 & $13.34 * *$ & 8.70 \\
\hline-14 & $10.34 * *$ & $9.47^{*}$ & 10 & $14.44 * *$ & $12.75^{* *}$ \\
\hline-13 & $13.15^{* *}$ & $11.23 * *$ & 11 & 10.37 & 5.72 \\
\hline-12 & 9.59 & 9.75 & 12 & $17.10^{* *}$ & $7.39 * *$ \\
\hline-11 & $11.29 * *$ & 6.51 & 13 & $12.24 * *$ & $10.40 * *$ \\
\hline-10 & $12.34^{*}$ & $9.98 * *$ & 14 & $18.74 * *$ & $11.82 * *$ \\
\hline-9 & 8.67 & $8.40 * *$ & 15 & $12.37 * *$ & 6.76 \\
\hline-8 & $13.17 * *$ & $9.25 * *$ & 16 & $10.10^{* *}$ & 7.86 \\
\hline-7 & 12.74 & $8.00^{* *}$ & 17 & $13.11^{* *}$ & $9.63 * *$ \\
\hline-6 & $11.41 *$ & $9.65 * *$ & 18 & $14.89 * *$ & $10.13 * *$ \\
\hline-5 & $10.61^{*}$ & $10.24^{* *}$ & 19 & 10.79 & 6.60 \\
\hline-4 & 11.85 & 9.41 & 20 & $16.49^{*}$ & $10.41 * *$ \\
\hline-3 & $14.95^{* *}$ & $11.14^{* *}$ & 35 & $11.86^{*}$ & $9.27 *$ \\
\hline-2 & $14.41^{* *}$ & $10.04 * *$ & 45 & $8.64^{*}$ & 6.68 \\
\hline-1 & $17.17 * *$ & $8.56^{*}$ & 55 & 8.87 & 2.06 \\
\hline
\end{tabular}

* The difference is statistically significant at the .95 confidence level.

** The difference is statistically significant at the .99 confidence level. 


\title{
Table VII
}

\section{Multivariate Analysis of Differences in the Relative Effective Spreads of Relocating Stocks and Their Controls Around Location Changes}

\begin{abstract}
The dependent variable is the difference in the relative effective spreads of a relocating stock and its control. The estimates shown are obtained from a fixed effects (event time) regression model. High AS is a binary variable taking the value of 1 if the relocating stock has higher-than-median level of adverse selection. Low MB is a binary variable taking the value of 1 if the fraction of NYSE floor brokers following a stock to its new location is less than the $75^{\text {th }}$ percentile for relocating stocks. (High AS)(Event Time) ${ }^{2}$ is an interactive variable between the High AS and the square of event time relative to the switch date. (Low MB)(Event Time) ${ }^{2}$ is an interactive variable between Low MB and the square of event time relative to the switch date. AS costs is the daily average of the difference between the effective and the realized spread for relocating stocks. Difference in Trade Size is the daily average difference between the trade size (in shares) of relocating stocks and their controls. Difference in \# of Trades is the daily average difference between the number of trades in relocating stocks and their controls. Difference in Trade Price is the daily average difference between the inverse of the trade price of relocating stocks and their controls. New Location Dummy is a binary variable taking the value of 1 for trades occurring on trading days after the location change. T statistics are shown in parentheses.
\end{abstract}

\begin{tabular}{|c|c|c|c|c|}
\hline & Model 1 & Model 2 & Model 3 & Model 4 \\
\hline Constant & $\begin{array}{l}-0.09^{* *} \\
(-21.62)\end{array}$ & $\begin{array}{l}-0.08 * * \\
(-19.08)\end{array}$ & $\begin{array}{l}-0.08 * * \\
(-20.07)\end{array}$ & $\begin{array}{l}-0.09 * * \\
(-20.03)\end{array}$ \\
\hline$($ High AS $)(\text { Event Time })^{2} \times 10^{6}$ & $\begin{array}{l}-2.24 * * \\
(-5.58)\end{array}$ & & $\begin{array}{l}-2.11 * * \\
(-5.28)\end{array}$ & $\begin{array}{l}-2.11 * * \\
(-5.27)\end{array}$ \\
\hline$(\text { Low MB)(Event Time })^{2} \times 10^{6}$ & & $\begin{array}{l}-1.60 * * \\
(-8.12)\end{array}$ & $\begin{array}{l}-1.34 * * \\
(-7.17)\end{array}$ & $\begin{array}{l}-1.35^{* *} \\
(-7.25)\end{array}$ \\
\hline AS Costs & $\begin{array}{l}0.47 * * \\
(22.12)\end{array}$ & $\begin{array}{l}0.46^{* *} \\
(23.01)\end{array}$ & $\begin{array}{l}0.47^{* *} \\
(22.13)\end{array}$ & $\begin{array}{l}0.47^{* *} \\
(22.09)\end{array}$ \\
\hline (Difference in Trade Size) $\times 10^{6}$ & $\begin{array}{l}0.92 * \\
(2.42)\end{array}$ & $\begin{array}{l}0.90^{*} \\
(2.37)\end{array}$ & $\begin{array}{l}0.90^{*} \\
(2.39)\end{array}$ & $\begin{array}{c}0.89 * \\
(2.38)\end{array}$ \\
\hline (Difference in \# of Trades) $\times 10^{6}$ & $\begin{array}{l}1.10^{* *} \\
(4.40)\end{array}$ & $\begin{array}{l}1.12 * * \\
(4.49)\end{array}$ & $\begin{array}{c}1.03 * * \\
(4.13)\end{array}$ & $\begin{array}{l}1.00 * * \\
(4.01)\end{array}$ \\
\hline $\begin{array}{l}\text { (Difference in Trade Price Inverse) } \\
\times 10^{6}\end{array}$ & $\begin{array}{l}3.08 * * \\
(57.45)\end{array}$ & $\begin{array}{l}3.08 * * \\
(57.18)\end{array}$ & $\begin{array}{l}3.08 * * \\
(57.56)\end{array}$ & $\begin{array}{l}3.06 * * \\
(56.12)\end{array}$ \\
\hline New Location Dummy & & & & $\begin{array}{c}0.02 * * \\
(11.52)\end{array}$ \\
\hline \# of Observations & 202,994 & 202,994 & 202,994 & 202,994 \\
\hline $\mathrm{R}^{2}$ & 0.22 & 0.22 & 0.31 & 0.31 \\
\hline
\end{tabular}

* The difference is statistically significant at the .95 confidence level.

** The difference is statistically significant at the .99 confidence level. 


\section{Table VIII}

Descriptive Statistics for Floor Trades Surrounding the Relocation of Stocks on the NYSE

Using the information available in the NYSE's Consolidated Equity Audit (CAUD) file, we classify counter-parties to trades as 'moving' or 'non-moving' brokers. Moving brokers (MB) participate in trades before and after a sample stock relocate on the NYSE floor. Non-moving brokers (NMB) participate in trades only during the pre-move or the post-move period. Event time is measured relative to the day on which the relocating stock first trades at its new location. By design, the specialist (SPEC) follows relocating stocks to their new location. Panel A: Average daily trading volume (in thousands).

\begin{tabular}{|c|c|c|c|c|c|c|c|}
\hline & \multicolumn{7}{|c|}{ Event Time } \\
\hline & -10 through -6 & -5 through -2 & -1 & 0 & +1 & +2 through +5 & +6 through +10 \\
\hline MB vs. SPEC & 2,622 & 3,247 & 3,091 & 2,548 & 2,629 & 2,379 & 3,021 \\
\hline MB vs. MB & 10,041 & 10,818 & 8,721 & 10,856 & 10,895 & 7,879 & 9,758 \\
\hline MB vs. NMB & 10,615 & 11,193 & 7,359 & 10,383 & 9,864 & 9,358 & 12,364 \\
\hline NMB vs. NMB & 28,488 & 24,366 & 17,573 & 23,769 & 27,117 & 36,362 & 24,953 \\
\hline NMB vs. SPEC & 12,098 & 11,722 & 9,058 & 10,728 & 9,349 & 10,077 & 10,973 \\
\hline All MB & 23,281 & 25,258 & 19,171 & 23,787 & 23,088 & 19,616 & 25,144 \\
\hline All NMB & 51,201 & 47,281 & 33,990 & 44,580 & 46,329 & 55,797 & 48,290 \\
\hline \multicolumn{8}{|c|}{ Panel B: Average trade size (shares). } \\
\hline & \multicolumn{7}{|c|}{ Event Time } \\
\hline & -10 through -6 & -5 through -2 & -1 & 0 & +1 & +2 through +5 & +6 through +10 \\
\hline MB vs. SPEC & 6,999 & 7,185 & 7,041 & 6,941 & 5,895 & 6,663 & 7,264 \\
\hline MB vs. MB & 23,009 & 22,414 & 20,765 & 25,543 & 22,604 & 21,129 & 24,138 \\
\hline MB vs. NMB & 5,706 & 5,414 & 5,403 & 5,708 & 6,216 & 6,376 & 5,412 \\
\hline NMB vs. NMB & 8,515 & 8,313 & 7,167 & 9,125 & 10,338 & 8,327 & 7,862 \\
\hline NMB vs. SPEC & 2,245 & 2,135 & 2,169 & 2,390 & 2,283 & 2,378 & 2,404 \\
\hline
\end{tabular}




\section{Table IX}

Share-Weighted Relative Effective Spreads for Moving and Non-Moving Brokers Before and After Stocks Relocate

We compute the share-weighted effective spread for trades handled by brokers relocating with the specialist and for trades handled by brokers who do not relocate with the specialist. The median values are obtained from the NYSE's CAUD database and are reported from event day -10 through event day +10 . Event day 0 is the first day of trading at the relocating stock's new location.

Panel A: Trades between a moving (non-moving) brokers and the specialist.

\begin{tabular}{|c|c|c|c|c|c|}
\hline \multirow{2}{*}{$\begin{array}{l}\text { Event } \\
\text { Time }\end{array}$} & \multicolumn{2}{|c|}{ Median Effective Spread (bps.) } & \multirow{2}{*}{$\begin{array}{l}\text { Event } \\
\text { Time }\end{array}$} & \multicolumn{2}{|c|}{ Median Effective Spread (bps.) } \\
\hline & Movers & Non-Movers & & Movers & Non-Movers \\
\hline-10 & 20.20 & 21.08 & 0 & 19.78 & $28.95^{*}$ \\
\hline-9 & 25.30 & 29.58 & 1 & 18.68 & $24.30 *$ \\
\hline-8 & 19.87 & $24.67 *$ & 2 & 27.23 & $32.72 *$ \\
\hline-7 & 21.75 & 21.03 & 3 & 28.19 & 30.69 \\
\hline-6 & 25.94 & 27.14 & 4 & 18.85 & $25.09^{*}$ \\
\hline-5 & 22.77 & $29.03 *$ & 5 & 21.74 & 21.65 \\
\hline-4 & 27.40 & 29.74 & 6 & 24.67 & 23.38 \\
\hline-3 & 24.51 & 19.58 & 7 & 31.04 & $36.71^{*}$ \\
\hline-2 & 20.98 & 21.53 & 8 & 25.95 & 21.68 \\
\hline \multirow[t]{2}{*}{-1} & 21.31 & $28.81^{*}$ & 9 & 20.14 & 18.97 \\
\hline & & & 10 & 29.40 & 26.11 \\
\hline \multicolumn{6}{|c|}{ Panel B: Trades between brokers. } \\
\hline \multirow{2}{*}{$\begin{array}{l}\text { Event } \\
\text { Time }\end{array}$} & \multicolumn{2}{|c|}{ Median Effective Spread (bps.) } & \multirow{2}{*}{$\begin{array}{c}\text { Event } \\
\text { Time }\end{array}$} & \multicolumn{2}{|c|}{ Median Effective Spread (bps. } \\
\hline & Both Movers & One Mover & & Both Movers & One Mover \\
\hline-10 & 29.72 & 29.63 & 0 & 29.47 & 28.08 \\
\hline-9 & 29.69 & 31.73 & 1 & 26.35 & $30.42 *$ \\
\hline-8 & 27.49 & 29.93 & 2 & 27.08 & $30.85^{*}$ \\
\hline-7 & 29.11 & $33.37 *$ & 3 & 28.34 & 29.63 \\
\hline-6 & 35.96 & 37.71 & 4 & 25.34 & 27.82 \\
\hline-5 & 29.47 & $33.23 *$ & 5 & 27.53 & $35.08^{*}$ \\
\hline-4 & 27.47 & $32.32 *$ & 6 & 31.20 & 29.98 \\
\hline-3 & 30.72 & 27.93 & 7 & 32.79 & 32.31 \\
\hline-2 & 26.22 & $29.81 *$ & 8 & 33.43 & 34.30 \\
\hline \multirow[t]{2}{*}{-1} & 28.57 & 31.16 & 9 & 29.49 & $33.29 *$ \\
\hline & & & 10 & 37.46 & 33.84 \\
\hline
\end{tabular}

* The difference between the effective spreads is statistically significant at the .95 confidence level.

** The difference between the effective spreads is statistically significant at the .99 confidence level. 


\section{Table X}

\section{Multivariate Analysis of Effective Spreads for Trades of}

Moving and Non-Moving Brokers Around Location Changes

The dependent variable is the effective spread paid by moving and non-moving brokers for trades with the specialist. The period covered is from event day -10 through event day +10 . Event day 0 is the first day that a relocation stock trades at its new location. Moving Broker is a binary variable that takes the value of 1 if the broker moves with the specialist and the value of 0 otherwise. The Hi Adverse Selection Dummy takes the value of 1 if the relocating stock has an above median level of adverse selection costs (measured as the difference between the stock's effective and realized spread) and the value of 0 otherwise. New Location Dummy is a binary variable taking the value of 1 for trades occurring on trading days after the location change. Trade Size is the size (in shares) of each trade and Trade Price is the inverse price of each trade. \# of Trades is the daily number of trades. T statistics are shown in parentheses.

\begin{tabular}{|c|c|c|c|}
\hline & Model 1 & Model 2 & Model 3 \\
\hline Constant & $\begin{array}{l}0.0925^{*} \\
(1.80)\end{array}$ & $\begin{array}{l}0.0652 \\
(1.37)\end{array}$ & $\begin{array}{l}0.0087 \\
(0.15)\end{array}$ \\
\hline Moving Broker & $\begin{array}{l}-0.1297 * * * \\
(-3.52)\end{array}$ & $\begin{array}{l}-0.0236 \\
(-1.44)\end{array}$ & $\begin{array}{l}-0.0214 \\
(-1.02)\end{array}$ \\
\hline$($ Moving Broker $)(\text { Event Time })^{2}$ & $\begin{array}{l}0.0006^{* * *} \\
(3.29)\end{array}$ & $\begin{array}{l}0.0006^{* * *} \\
(2.16)\end{array}$ & $\begin{array}{l}0.0006 * * * \\
(2.30)\end{array}$ \\
\hline (Moving Broker)(Hi Adverse Selection Dummy) & $\begin{array}{l}-0.2054 * * * \\
(-3.18)\end{array}$ & $\begin{array}{l}-0.1906 * * * \\
(-3.24)\end{array}$ & $\begin{array}{l}-0.1946 * * * \\
(3.08)\end{array}$ \\
\hline (Moving Broker)(New Location Dummy) & $\begin{array}{l}0.1811 * * * \\
(3.60)\end{array}$ & & \\
\hline High Adverse Selection Dummy & $\begin{array}{l}0.0237 \\
(0.59)\end{array}$ & $\begin{array}{l}0.0218 \\
(0.53)\end{array}$ & $\begin{array}{l}0.0202 \\
(0.48)\end{array}$ \\
\hline$\left(\right.$ Trade Size) $\times 10^{6}$ & $\begin{array}{l}0.0548 * \\
(1.90)\end{array}$ & $\begin{array}{l}0.0500 \\
(1.62)\end{array}$ & $\begin{array}{l}0.0511 * \\
(1.74)\end{array}$ \\
\hline Trade Price Inverse & $\begin{array}{l}9.5733 * * * \\
(6.53)\end{array}$ & $\begin{array}{l}9.6086^{* * *} \\
(6.46)\end{array}$ & $\begin{array}{l}9.6644 * * * \\
(6.29)\end{array}$ \\
\hline (\# of Trades) $\times 10^{6}$ & $\begin{array}{l}-0.0001 \\
(-0.62)\end{array}$ & $\begin{array}{l}-0.0001 \\
(-0.60)\end{array}$ & $\begin{array}{l}-0.0000 \\
(-0.17)\end{array}$ \\
\hline New Location Dummy & $\begin{array}{l}-0.1256 * * \\
(-2.15)\end{array}$ & $\begin{array}{l}-0.0824 \\
(-1.63)\end{array}$ & \\
\hline $\mathrm{R}^{2}$ & 0.338 & 0.333 & 0.328 \\
\hline
\end{tabular}


Figure 1

Median Differences in the Share-Weighted

Relative Effective Spreads of Relocating Stocks and Their Controls

All Movers

Movers with HighAdrerse Selection

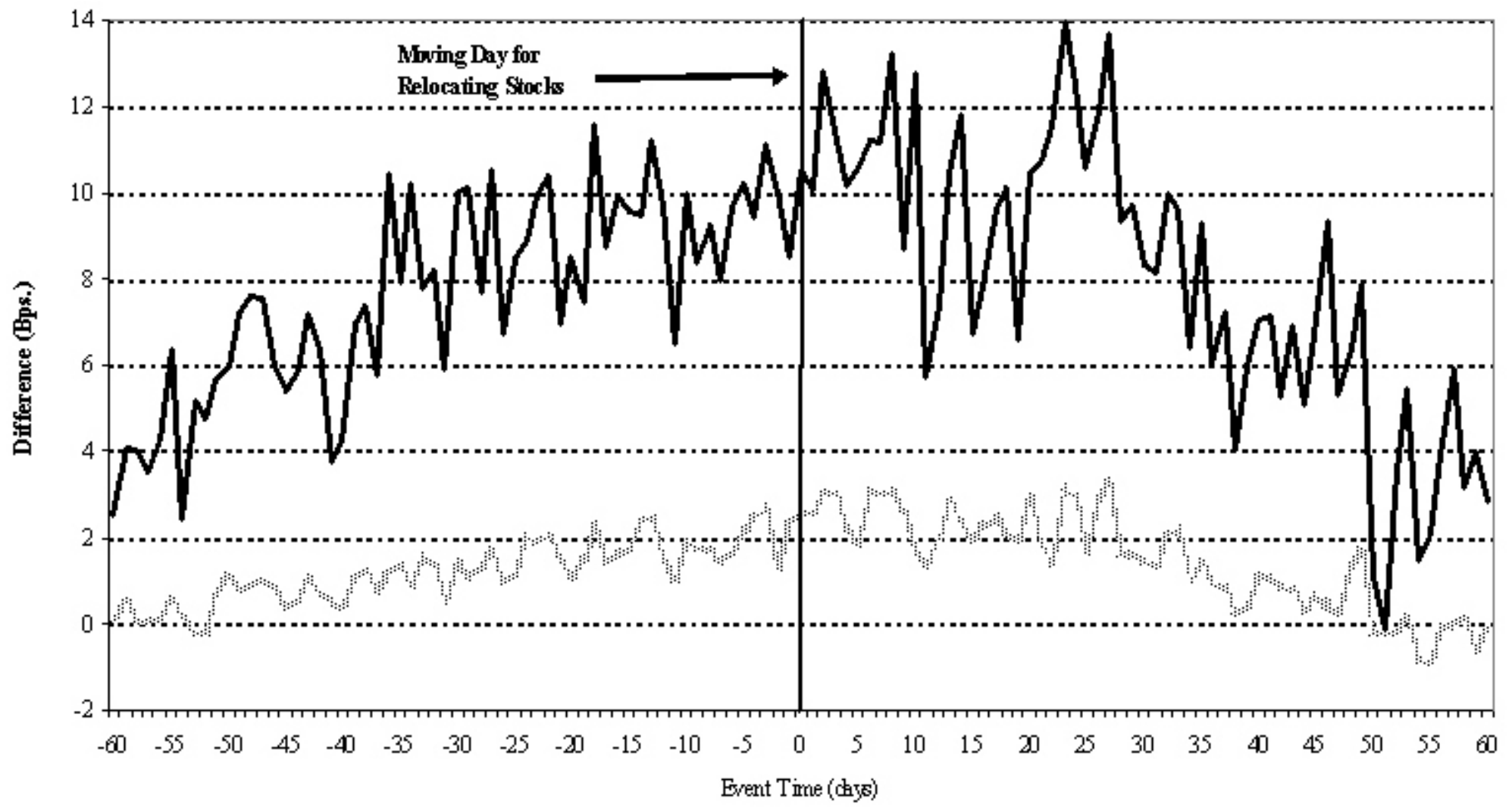


Figure 2

Median Differences in the Share-Weighted Relative Effective Spreads of Relocating Stocks and Their Controls for the Four Largest Relocations

June1, 2000 Mbe (l=100)

Nowerber 20, $200 \mathrm{Mbe}(1=410)$

. . . Deomber 11, 2000 Mbe $(1=300)$

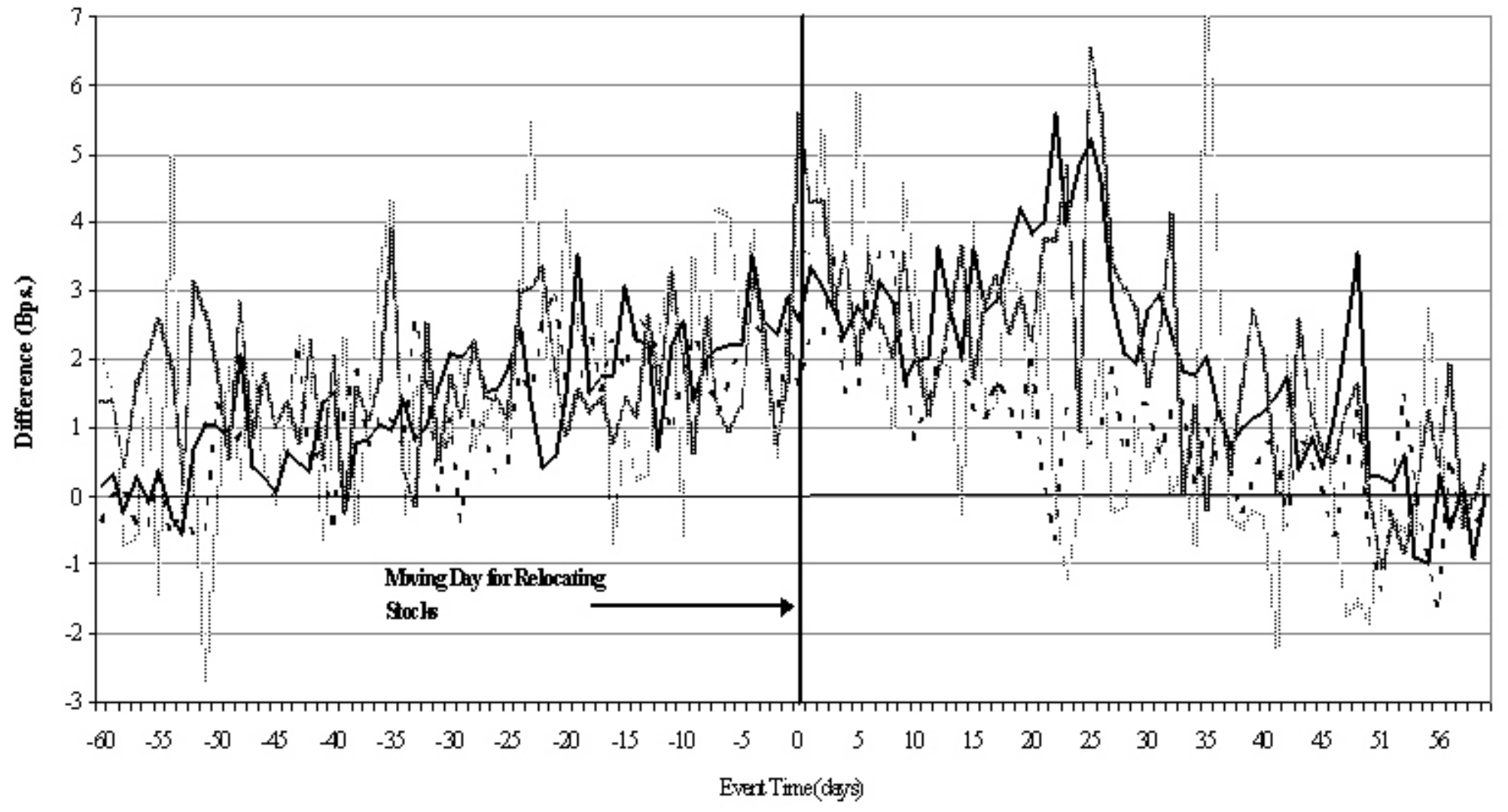


Figure 3

Median Differences in the Share-Weighted

Relative Realized Spreads of Relocating Stocks and Their Controls

H All Mbers

- Mvers with High Adverse Selection

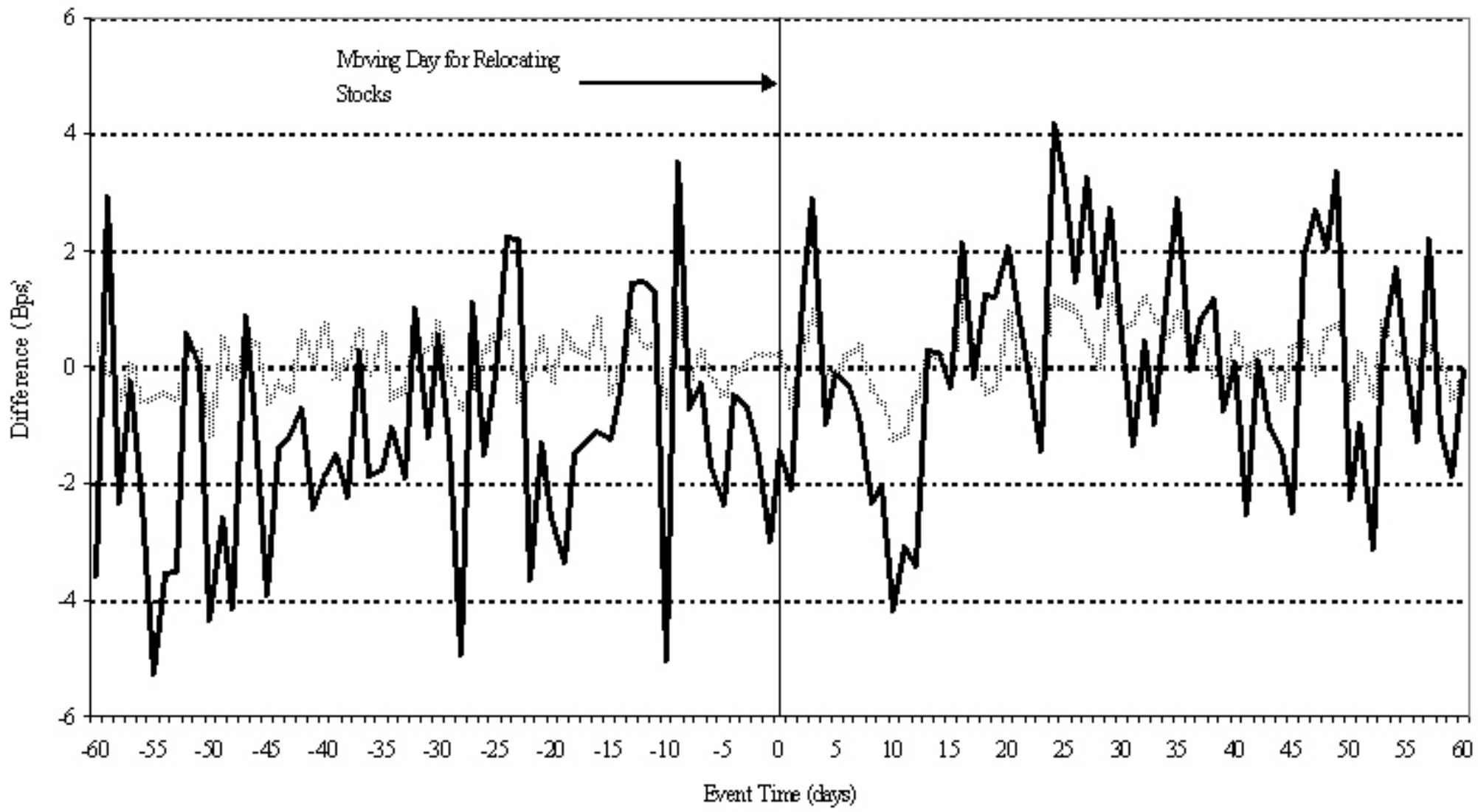

